\title{
Modular Hybrid Plasma Reactor for Low Cost Bulk Production of Nanomaterials
}

\author{
Peter Kong
}

December 2011

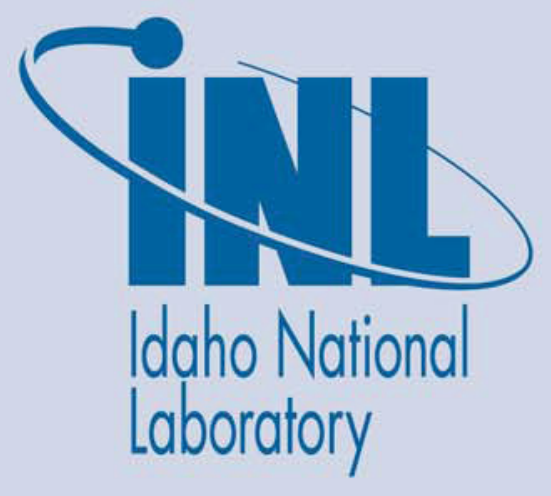

The INL is a U.S. Department of Energy National Laboratory operated by Battelle Energy Alliance 


\section{DISCLAIMER}

This information was prepared as an account of work sponsored by an agency of the U.S. Government. Neither the U.S. Government nor any agency thereof, nor any of their employees, makes any warranty, expressed or implied, or assumes any legal liability or responsibility for the accuracy, completeness, or usefulness, of any information, apparatus, product, or process disclosed, or represents that its use would not infringe privately owned rights. References herein to any specific commercial product, process, or service by trade name, trade mark, manufacturer, or otherwise, does not necessarily constitute or imply its endorsement, recommendation, or favoring by the U.S. Government or any agency thereof. The views and opinions of authors expressed herein do not necessarily state or reflect those of the U.S. Government or any agency thereof. 


\title{
Modular Hybrid Plasma Reactor for Low Cost Bulk Production of Nanomaterials
}

\author{
Peter Kong
}

December 2011

Idaho National Laboratory Energy Efficiency and Industrial Technology Department Idaho Falls, Idaho 83415

http://www.inl.gov

Prepared for the

U.S. Department of Energy

Office of Energy Efficiency and Renewable Energy

Under DOE Idaho Operations Office

Contract DE-AC07-05ID14517 


\section{EXECUTIVE SUMMARY}

INL developed a bench-scale, modular hybrid plasma system for gas-phase nanomaterials synthesis. The system was optimized for $\mathrm{WO}_{3}$ nanoparticle production and scale-model projection to a $300 \mathrm{~kW}$ pilot system. During the course of technology development, many modifications were made to the system to resolve technical issues that surfaced and also to improve performance. All project tasks were completed except two optimization subtasks. Researchers were unable to complete these two subtasks, a four-hour and an eight-hour continuous powder production run at $1 \mathrm{lb} / \mathrm{hr}$ powder-feeding rate, due to major technical issues developed with the reactor system. The 4-hour run was attempted twice, and on both occasions, the run was terminated prematurely. The termination was due to (1) heavy material condensation on the modular electrodes, which led to system operational instability, and (2) pressure buildup in the reactor due to powder clogging of the exhaust gas and product transfer line. The modular electrode for the plasma system was significantly redesigned to address the material condensation problem on the electrodes. However, the cause for product powder clogging of the exhaust gas and product transfer line led to a pressure build up in the reactor that was undetected. Fabrication of the redesigned modular electrodes and additional components was completed near the end of the project life. However, insufficient resource was available to perform tests to evaluate the performance of the new modifications. More development work would be needed to resolve these problems prior to scaling.

The technology demonstrated a surprising capability of synthesizing a single phase of meta-stable $\delta$ $\mathrm{Al}_{2} \mathrm{O}_{3}$ from pure $\alpha$-phase large $\mathrm{Al}_{2} \mathrm{O}_{3}$ powder. The formation of $\delta-\mathrm{Al}_{2} \mathrm{O}_{3}$ was surprising because this phase is meta-stable and only formed between $973-1073 \mathrm{~K}$, and $\delta-\mathrm{Al}_{2} \mathrm{O}_{3}$ is very difficult to synthesize as a single phase. Besides the specific temperature window to form this phase, this meta-stable phase may have been stabilized by nanoparticle size formed in a high-temperature plasma process. This technology may possess the capability to produce unusual meta-stable nanophase materials that would otherwise be difficult to produce by conventional methods.

A $300 \mathrm{~kW}$ INL modular hybrid plasma pilot-scale model reactor was projected using the experimental data from PPG Industries' $300 \mathrm{~kW}$ hot-wall plasma reactor. The projected size of the INL $300 \mathrm{~kW}$ pilot model reactor would be about 15\% that of the PPG $300 \mathrm{~kW}$ hot-wall plasma reactor. Including the safety-net factor, the projected INL pilot-reactor size would be $25-30 \%$ of the PPG $300 \mathrm{~kW}$ hot-wall plasma pilot reactor. Due to the modularity of the INL plasma reactor and the energy-cascading effect from the upstream plasma to the downstream plasma, the energy utilization is more efficient in material processing. It is envisioned that the material throughput range for the INL pilot reactor would be comparable to the PPG $300 \mathrm{~kW}$ pilot reactor, but energy consumption would be lower.

The INL hybrid plasma technology is rather close to being optimized for scaling to a pilot system. More near-term development work is still needed to complete the process optimization before pilot scaling.

\section{Final Report Task Summary}

There are five major tasks with sub tasks in this project, and all tasks have been performed.

\section{Task 1 Assess, choose, and run one model material to demonstrate 100\% optimization within 18 months}

a. Choose one material for process optimization demonstration

Status: Completed

b. Optimize insulations and configuration design to maximize thermal insulation efficiency 
Status: Completed

c. Demonstrate complete vaporization (100\%) of large and small feed powder for the one chosen model material

Status: Completed

d. Demonstrate a narrow particle size distribution, 5-50 $\mathrm{nm}$ range

Status: Completed, but size range [1-80 nm] is wider than the target range

e. Demonstrate minimum fouling (free or minimum condensed material) for all modular plasma torch components

Status: Completed but with mixed results. For short duration runs, fouling of the modular plasma torch component is minimal.

\section{Task 2 Preliminary runs for the one chosen model material}

Status: Completed

\section{Task 3 Production Process and Pre-Pilot System Operations Trouble Shooting Runs}

Status: Completed

\section{Task 4 Pre-pilot Production Process and System Optimization \& other materials Demonstrations}

a. Demonstrate sustained $1 \mathrm{lb} / \mathrm{hr}$ powder feed rate of model material while meeting requirements of tasks 1c through 1e

Status: Completed. The technology demonstrated a sustained powder feed rate at $>1 \mathrm{lb} / \mathrm{hr}$ for long-duration synthesis runs.

b. Demonstrate at least $90 \%$ mass balance

Status: Completed

c. Demonstrate sustained runs of 2 hours, 4 hours, and 8 hours while meeting requirement of tasks $4 a \&$ $4 \mathrm{~b}$

Status: Partially completed, with mixed results. Two-hour run was successful. Two four-hour runs were not completely successful due to condensed-material fouling the modular reactor components, which presented undesirable operational instability for the system. The modular plasma torch system was completely redesigned to resolve this condensed-material fouling problem. The new design was very complex, and machine-shop crafts had difficulties fabricating very intricate components. During fabrication, many design errors were discovered, and the draftsman had to make many adjustments and modifications to the design drawings. Therefore, many components had to be reworked or rebuilt. The new modular hybrid plasma torch was completed close to the end of the project performance period, when project resources and time were exhausted. As a result, additional fourhour runs and the planned eight-hour run were not performed.

d. Demonstrate synthesis of other materials

Status: Completed. Other materials synthesis had been successfully demonstrated. A pure singlephase meta-stable material was unexpectedly synthesized. The capability of this technology to synthesize unusual materials that cannot be synthesized by conventional methods is demonstrated.

Task 5 Scale up modeling and validate $300 \mathrm{~kW}$ size

Status: Completed 


\section{CONTENTS}

EXECUTIVE SUMMARY iiv

ACRONYMS $\mathrm{x}$

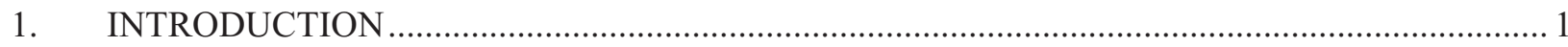

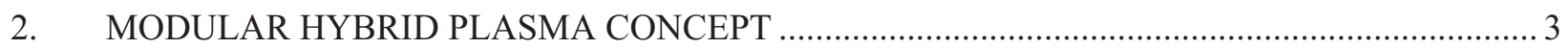

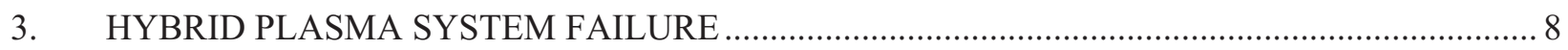

4. HYBRID PLASMA SYSTEM POWER CYCLING TEST ...................................................... 10

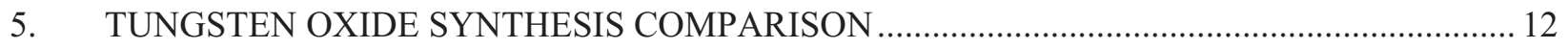

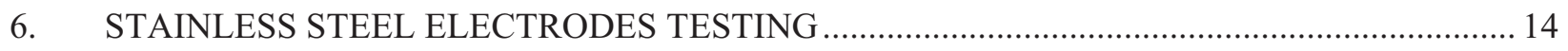

7. TUNGSTEN OXIDE SYNTHESIS WITH NEW MODULAR ELECTRODE DESIGN............... 16

7.1 Run 227 1-Hour Run................................................................................................... 21

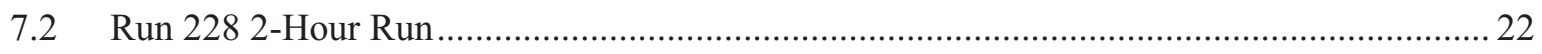

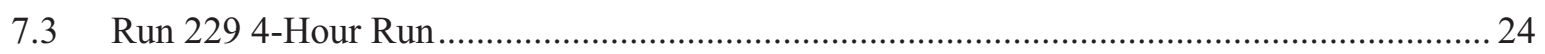

7.4 Unsuccessful Second 4-Hour Runs ............................................................................. 26

7.5 New Modified Modular Plasma Reactor............................................................................. 28

7.6 INL 300 kW Pilot Scale Model Projection ....................................................................... 29

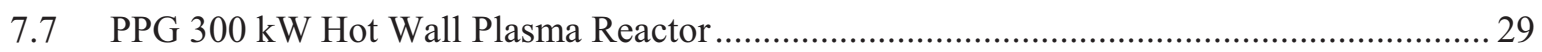

7.8 INL 300 kW Modular Hybrid Plasma Scale Model Projection .......................................... 31

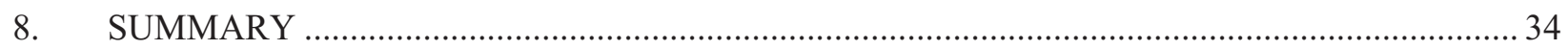

\section{FIGURES}

Figure 1. GEN II is a 2-modular unit hybrid plasma system. ................................................................ 3

Figure 2. The generation IV modular hybrid plasma system............................................................... 3

Figure 3. GEN V is shown with a $\mathrm{WO}_{3}$ powder vaporization test. ...................................................... 4

Figure 4. Nanoparticles of $\mathrm{WO}_{\mathrm{x}}$ leaving the plasma flame condensed on the glass plate of the expansion chamber and partially blocked the view of the window............................................ 4

Figure 5. Starting $\mathrm{WO}_{3}$ is shown on the left and the plasma processed $\mathrm{WO}_{\mathrm{x}}$ are shown to the right. For similar mass material the products showed significant volume increase.............................. 4

Figure 6. Comparison of nanoparticles produced under different conditions............................................5

Figure 7. The arc root instability caused the plasma tail flame to fluctuate and breaks up....................... 6

Figure 8. With a stable arc root attachment the plasma tail flame is more stable and extended................. 6

Figure 9. Modular cathode assembly shows the molten droplets formed on the surface of the tungsten electrode. 
Figure 10. Enlarged view of the tungsten cathode surface and the elongated shape of the molten drop indicated the direction of arc rotation.

Figure 11. The modular anode assembly showed a much smoother surface on the tungsten ring electrode...

Figure 12. The original modular electrode assembly used a press fitted tungsten ring electrode................ 8

Figure 13. The new configuration is a segmented modular electrode assembly. Both anode and cathode use the same design.

Figure 14. The left photo show the anode and the right photo showed the fractured cathode during the high temperature brazing process.

Figure 15. The new design for the modular electrode assembly used a mechanical mating joint......

Figure 16. Run 206 GEN IV modular hybrid plasma power cycle test with both upstream and modular torches varying.

Figure 17. Run 207 GEN IV modular hybrid plasma power cycle test with constant upstream plasma power.

Figure 18. Run 208 GEN IV modular hybrid plasma power cycle test with higher varying modular plasma power.

Figure 19. X-ray diffraction analysis of Test 210 and the run conditions were 400A and 30V............... 12

Figure 20. X-ray particle size analysis using peak width at half peak maxima for tests 210 to 212 .......... 13

Figure 21. Average particle size comparison between starting $\mathrm{WO}_{3}$ and runs 210 to $212 \ldots \ldots \ldots \ldots \ldots \ldots \ldots . . . . . . . . .13$

Figure 22. Real time data for hybrid run 214 using stainless steel electrodes. ......................................... 14

Figure 23. Condition of the cathodes after run, (a) tungsten cathode showed the arc rotation streaks on the surface, and (b) SS cathode shows significantly more erosion because of lower melting temperature.

Figure 24. Condition of the tungsten anode (a) and SS anode (b) after tests, both anodes showed no sign of erosions because of diffused arc attachment and rotation of the arc roots.

Figure 25. Particle size comparison between starting $\mathrm{WO}_{3}$, nonhybrid plasma processed $\mathrm{WO}_{3}$, and hybrid plasma processed $\mathrm{WO}_{3}$

Figure 26. Real time data for hybrid runs $218 \& 220$ with tungsten electrodes for $\mathrm{WO}_{3}$ processing. Run 218 ran with $200 \mathrm{~V}$ open voltage for the modular unit. Run 220 ran with $400 \mathrm{~V}$ open voltage for the modular unit.

Figure 27. In hybrid run $220 \mathrm{WO}_{3}$ nanoparticle fumes are seen leaving the hybrid plasma tail flame.

Figure 28. Volume change comparison for feed and plasma processed $\mathrm{WO}_{3}$ powders using different plasma reactor configurations. T212 used a conventional plasma torch, T216 used the upstream plasma torch only in the hybrid plasma reactor configuration, and T225 used the full hybrid plasma reactor operation mode.

Figure 29. The current, voltage and power of the hybrid run $\mathrm{T} 225$ for $\mathrm{WO}_{3}$ production were shown in (a), and the temperature measurement for all components in the hybrid system was shown in (b).

Figure 30. SEM micrographs for the (a) starting $\mathrm{WO}_{3}$ particles, (b) hybrid plasma produced $\mathrm{WO}_{3}$ nanoparticles, and (c) higher magnification of the nanoparticles. 


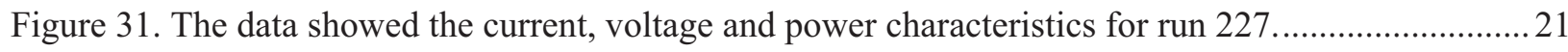

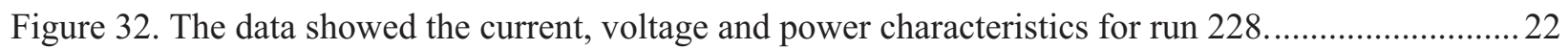

Figure 33. (a), (b), and (c) TEM morphologies of the $\mathrm{WO}_{3}$ nanoparticles synthesized using the modular hybrid plasma system.

Figure 34. (a) Showed the powder suspended in the chamber at the beginning of run 228 and the color of the plasma light is slightly bluish, and (b) showed the collection chamber window had a substantial layer of nanoparticles condensed on the surface 5 minutes into run 228 and nothing was observable through the chamber window.

Figure 35. Conditions of the modular plasma electrodes after the 2-hour run (a) the cathode assembly, (b) the modular anode assembly, and (c) anode exit.

Figure 36. $\mathrm{WO}_{3}$ nanoparticles collected in the (a) collection chamber and (b) the bag filter. ......

Figure 37. The data showed the current, voltage and power characteristics for run 229 before the run was terminated.....

Figure 38. (a) A hole was drilled at the junction between the ceramic plate between the modular cathode and the arc channel, and (b) the ceramic plate was also cracked due to thermal stress.

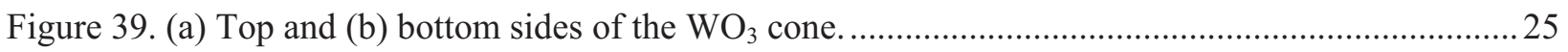

Figure 40. The thick coating formed on the cathode channel. ..............................................................2 25

Figure 41 . Terminated $2^{\text {nd }} 4$-hour run showed the high voltage spikes. During voltage spikes the current drop was rather small and joule heating was maintained.

Figure 42. A semi-porous powder plug formed in the transfer line and the powder collected in the bag filter.

Figure 43. Both the cathode and anode channels showed heavy coating of tungsten oxide covering the tungsten ring electrodes. The coating caused significant arc voltage fluctuations.

Figure 44. New designs of the modular plasma torch system............................................................. 27

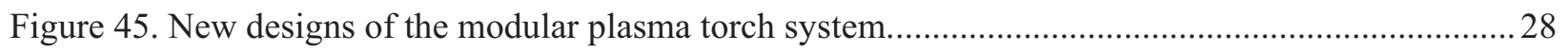

Figure 46. The new modular hybrid plasma torch consists of gas breathing hollow ring electrodes for electrode surface cleaning.

Figure 47. The new modular cathode assembly with a hollow ring electrode and a gas delivery component attached to the top of the assembly.

Figure 48. PPG hot wall plasma reactor.

Figure 49. Model Temperature profiles for the PPG $300 \mathrm{~kW}$ hot-wall plasma reactor

Figure 50. PGG modeling result of the $300 \mathrm{~kW}$ plasma hot wall reactor showed the temperature and time profiles for gas and particles.

Figure 51. PGG modeling result of the $300 \mathrm{~kW}$ plasma hot wall reactor shows the temperature and distance profiles for gas and particles.

Figure 52. Schematics of the INL $300 \mathrm{~kW}$ one modular unit hybrid plasma pilot reactor. 


\section{TABLES}

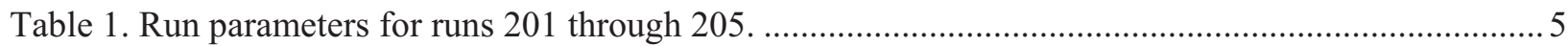

Table 2. Run summary of the modular hybrid plasma system................................................................ 18

Table 3. Volume change comparison for feed and plasma processed $\mathrm{WO}_{3}$ particles using different

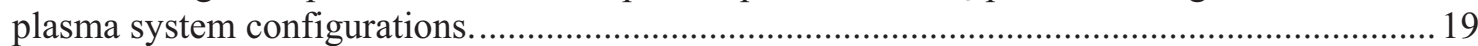

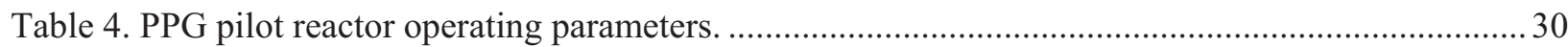

Table 5. Efficiencies for the INL modular hybrid plasma system (1 modular plasma unit used

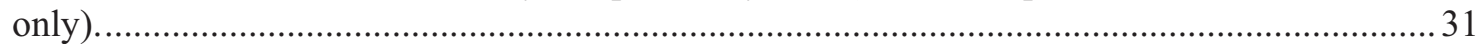

Table 6. INL Bench Scale Modular Hybrid Plasma Reactor Operating Parameters for $\mathrm{WO}_{3}$ synthesis process optimization. 


\section{ACRONYMS}

ARRA American Recovery and Reinvestment Act

BET Brunau, Emmett, and Teller analysis

DARPA Defense Advanced Research Projects Agency

DOE Department of Energy

HQ headquarters

INL Idaho National Laboratory

NETL National Energy Technology Laboratory

TEM transmission electron microscopy 


\section{Modular Hybrid Plasma Reactor for Low Cost Bulk Production of Nanomaterials}

\section{INTRODUCTION}

Idaho National Laboratory (INL) has developed a bench-scale, modular hybrid plasma reactor to synthesize nanomaterials. PPG Industries is interested in testing the capability of this bench-scale reactor for low-cost bulk production of nanomaterials. PPG Industries also wishes to assess the market potential to build a business line based on this technology. In FY2008, INL and PPG submitted a joint proposal responding to a DOE EERE Industrial Technology Program Nanomanufacturing Initiative call to develop and optimize this technology for potential industrial applications. The proposal was selected, and the project was authorized under the American Recovery and Reinvestment Act (ARRA) funding at the end of FY 2009.

On September 02, 2009, a kickoff meeting for the ARRA project, "Modular Hybrid Plasma Reactor and Process for Low Cost Nanoparticle Production," was held with the industrial partner. The INL project team presented the original task plan in the winning proposal. However, between the time of submission and project award, a major development occurred outside the control of PPG Industries. Due to the severe economic downturn in late 2008, PPG Corporate was forced to close and offloaded the planned pilot system demonstration site at the PPG Longmont facility in Colorado. The pilot demonstration site had been the planned host for a duplicated pre-pilot modular hybrid plasma system. The duplicate system would expedite the research effort by increasing the number of runs on test materials.

With the loss of the PPG Longmont facility, the INL team presented a revised project task plan. The revised project task plan redirected all effort to INL to maximize the opportunity to optimize the pre-pilot modular hybrid plasma reactor at INL. The discussion was centered on the selection of a material that would have a high probability to adequately test the INL pre-pilot system and also supported a successful demonstration of the selected material within the project life. The final phase of this project would showcase the technology's capability to process other materials and model the pre-pilot scale to the 300 $\mathrm{kW}$ pilot. The INL team presented several model materials for consideration. Based on material properties, both teams agreed that $\mathrm{WO}_{3}$ (tungsten oxide) was the ideal material that would best fit a new PPG-business-model product line. This material was then chosen to optimize the INL pre-pilot reactor system, as well as the pilot-size modeling effort. The revised project plan did not change the project intent, budget, technical objectives, or deliverables identified in the original proposal.

During discussions, PPG revealed that they had sub-contracted another company on a Defense Advanced Research Projects Agency (DARPA) project to evaluate a 300KW hot-wall plasma reactor. The PPG DARPA project was directed at the production of a nanomaterial for light armor applications. PPG would design, build, test, and demonstrate a pilot-scale hot-wall reactor powered by a $300 \mathrm{KW}$ reversed-polarity plasma torch supplied by the other company. PPG informed INL that they would not have access to this $300 \mathrm{KW}$ reversed-polarity plasma torch for the commercial production of nanomaterials because it was a test system only. However, the other company would lease the plasma equipment to interested parties for demonstration tests. Comments from PPG indicated that this reversedpolarity plasma reactor system was neither as efficient nor as versatile as the INL modular hybrid plasma system. PPG would make test runs on $\mathrm{WO}_{3}$ using the $300 \mathrm{~kW}$ hot-wall plasma rector and provided the technical data to guide INL's effort to model the $300 \mathrm{~kW}$ pilot-scale modular hybrid plasma reactor. 
After the meeting with PPG, the INL project team traveled to National Energy Technology Laboratory (NETL) and visited the project manager, Mr. Joseph Renk. The PI briefed the project manager on the meeting with PPG and presented the revised project plan. Mr. Renk advised the PI to send him a formal update following discussions at NETL for transmittal to DOE HQ Program Office. The revised project plan was transmitted to the HQ program office through the NETL project office in October 2009 for HQ guidance. 


\section{MODULAR HYBRID PLASMA CONCEPT}

The concept of modular hybrid plasma was to stack two or more modular plasma torches in tandem in order to lengthen the plasma column and, thus, increase the processing time for materials introduced into plasma column. In our specific definition, hybrid meant that the "field free" (current and voltage free) plasma jet from the upstream unit was reheated to a "field active" (current and voltage active) arc state by superimposing an electric discharge in the downstream plasma units. The modular configuration allowed one to manipulate the power settings in each of the modular units to achieve the desired temperature levels. One could add or subtract modular units to achieve the desired residence time for complete vaporization of the feed materials. The modular plasma torch might be described as an open tubular electrode design. The electrodes were tungsten rings placed within tubular copper housing assemblies. Material could continuously flow from one modular unit into the next.

The modular plasma system had gone through several generations of development, from GEN I to GEN IV. GEN I is a single modular unit hybrid plasma system with a 0.75 -in. electrode ring diameter. The arc channel diameter between the modular cathode and anode was $1 \mathrm{in}$. and was made of water-cooled double-wall quartz tube. The quartz arc channel facilitated the observation of the arc in operation. The GEN II was a two modular unit hybrid plasma system with dimensions identical to

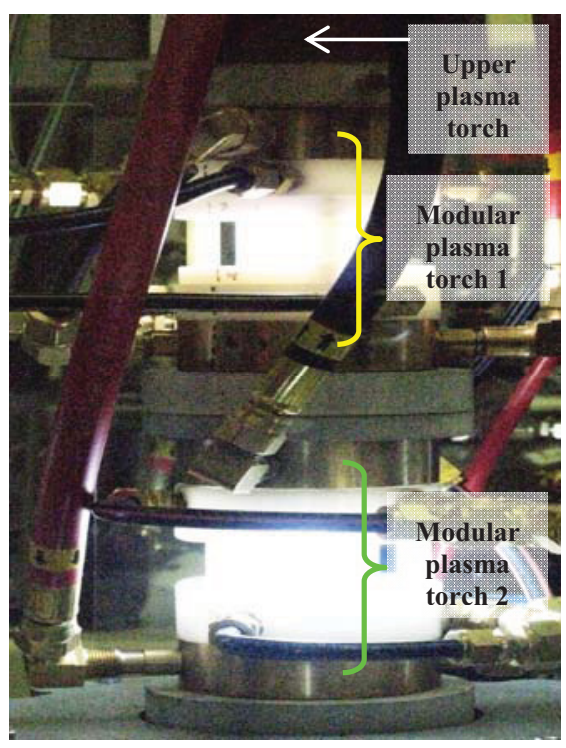

Figure 1. GEN II is a 2-modular unit hybrid plasma system. GEN 1. Figure 1 shows the GEN II modular hybrid plasma system in operation. Both modular plasma units were operated at the same power setting. One can clearly see that the plasma intensity in the bottom modular plasma unit was much brighter than the top modular plasma unit. This was due to the energy-cascading effort from the upstream plasma subsystems. There was a major redesign for the next generation, the GEN III, in order to perform system capability studies for

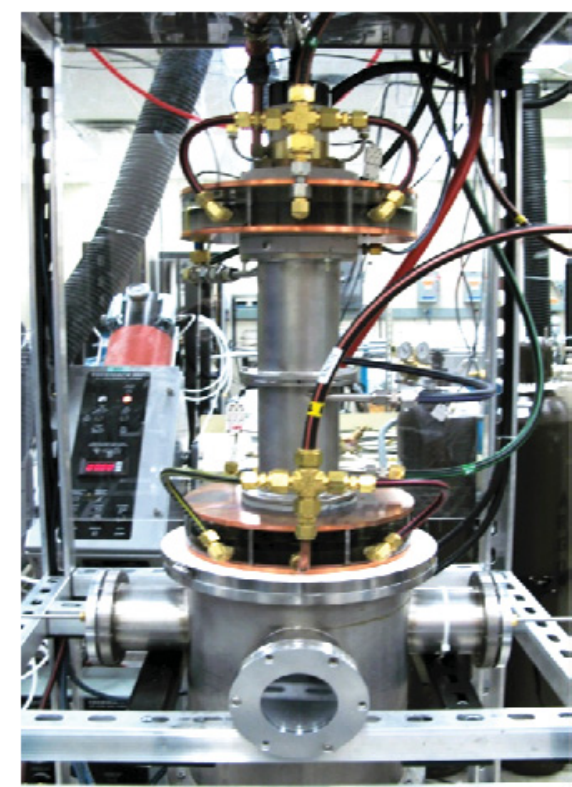

Figure 2. The generation IV modular hybrid plasma system. material processing. GEN III used a ceramic-insulated metal arc channel for arc confinement. The diameters of the anode and cathode rings and the arc channel in GEN III were increased to 1.125 in. for material vaporization tests. Two arc channel lengths, 6 in. and 12 in., were tested for large refractory powders vaporization. At $12 \mathrm{in}$. length, the arc voltage almost doubled that of the $6 \mathrm{in}$. arc length. One-hundred-percent complete vaporization of the feed was not achieved even with the longer arc length. A GEN IV hybrid plasma system was designed to further increase the residence of the feed material in the arc column. In GEN IV, the electrode ring and arc channel diameters were increased to $1.5 \mathrm{in}$. Increasing the channel diameter from $1.125 \mathrm{in}$. to $1.5 \mathrm{in}$, the residence time of feed powders in the arc column was increased by 1.78 times under the same plasma flow condition. Figure 2 shows the GEN IV hybrid plasma system. The total arc length between the cathodic and anodic arc roots was 15.25 in. In GEN IV, large feed powders of refractory oxides such as alumina and silica achieved more than $90 \%$ vaporization. The result indicated that the residence time for the feed powder in the plasma should be increased further to achieve $100 \%$ vaporization. Longer residence time could be achieved either by using an arc 
channel $>12$ in. or further increasing the arc channel diameter. The plasma system is limited by its physical height; therefore, GEN V was designed with a 1.75 in. arc channel diameter. Increasing the arc channel diameter from GEN III (1.125 in.) to GEN V (1.75 in.), the residence time of feed powders in the same arc column increased by 2.42 times under identical plasma-flow conditions.

In this project, GEN V was used for the pre-pilot bench scale process and system optimization and for the $300 \mathrm{~kW}$ pilot-scale model projection. GEN V was a short arc system with a 9.25 in. hybrid arc length and an arc channel diameter of $1.75 \mathrm{in}$. The model material identified and chosen for the process and system optimization was tungsten oxide, $\mathrm{WO}_{3}$. Preliminary runs were completed for $\mathrm{WO}_{3}$ in the GEN V pre-pilot bench-scale modular hybrid plasma reactor to understand material-run characteristics and the system responses. Results showed that the 9.25 in. hybrid arc length was sufficient to fully vaporize the $\mathrm{WO}_{3}$ feed. Figure 3 shows the GEN V hybrid plasma system during a $\mathrm{WO}_{3}$ powder vaporization test. Before $\mathrm{WO}_{3}$ injection into the reactor, the plasma was bright white, and after powder injection, the plasma was colored yellow and orange. Figure 4 shows the color and shape of the plasma during a $\mathrm{WO}_{3}$ production run. Due a special current path configuration designed for the electrodes, the arc root attachments were stabilized by a self generated magnetic field, and the arc column was rotated by moving charges in the current path. This special electrode current path invention eliminated the need for external magnetic field coils for arc rotation and thus reduced energy consumption for materials production. At a high powder-feed rate, $1.42 \mathrm{lb} / \mathrm{hr}$, the window was quickly blocked by condensed nanoparticles. In Figure 4, the visibility of the plasma plume is partially blocked by $\mathrm{WO}_{3}$

nanoparticles coated on the window. Figure 5 shows a comparison of the volume of the starting material and the products. The products showed a 4 to 5 times volume increase for similar mass weight. The targeted volume increase for the processed material was $\geq 10 \times$.

The $\mathrm{WO}_{3}$ synthesized appeared dark blue and was different from the pale yellow-green of the feed powder. The color change was due to a slight reduction of the oxide from $\mathrm{WO}_{3}$ to $\mathrm{WO}_{3-\mathrm{x}}$. In these runs the arc channel liner was made of graphite and, under the intense arc temperature, the graphite became slightly volatile. The carbon vapor provided a mildly reducing environment to reduce the $\mathrm{WO}_{3}$ to nonstoichiometric suboxides. It is well known that tungsten oxide can form several suboxides, $\mathrm{WO}_{2.72}$ and $\mathrm{WO}_{2.90-2.97} \mathrm{WO}_{2.72}$ is a dark charcoal grey oxide. $\mathrm{WO}_{2.90-2.99}$ is called the blue oxide, and its color 
ranged from dark blue $\left(\mathrm{WO}_{2.90}\right)$ to light blue $\left(\mathrm{WO}_{2.99}\right)$. Figure 6 shows the nonstoichiometric tungsten suboxides synthesized. $\mathrm{WO}_{3}$ was known to exhibit a color change from yellow to dark blue when the oxygen composition deviates from 3 to 2.72 . Due to its rich yellow color, $\mathrm{WO}_{3}$ is also used as a pigment in ceramics and paints. In recent years, $\mathrm{WO}_{3}$ was employed in the production of electrochromic windows, or smart windows. These windows are electrically switchable glass that changes light transmission properties with an applied voltage. This allows the user to tint windows, changing the amount of heat or light passing through.

When quench air was used at the exit of the modular plasma unit, the nanoparticles reoxidized to the original $\mathrm{WO}_{3}$ composition. Runs 201 through 205 showed the effect of quench air. Run 201 had no quench air, and the powder was dark blue. Run 202 used a low amount of quench air, and there was some light blue powder mixed with the dark blue powder. The oxygen content was far from sufficient to completely reoxidize the suboxides to $\mathrm{WO}_{3}$. The quench air in runs 203 and 204 was significantly increased, and the products turned lighter blue. However, the oxygen content was still not sufficient to complete the oxidation of all the suboxides. In run 205, pure oxygen quench gas was used, and the product was drastically different from the other runs. The color of the powder was pale bluish green, and the composition was very close to $\mathrm{WO}_{3}$.

Runs 203 and 204 achieved more size reduction of the feed particles. Run 205 had the least size reduction of the feed compared to other runs. The run parameters for these runs were shown in Table 1. There was a steady trend to increase the system total power to investigate feed particle size reduction under a constant system configuration. At this pre-pilot stage, the total system efficiency was not very high. The measured total system efficiency is between 10.42 to $30.62 \%$, depending on total system power input. Taking an average system efficiency of $20 \%$, the actual power in the plasma to process the feed powder is shown in parenthesis in the table.

Table 1. Run parameters for runs 201 through 205.

\begin{tabular}{ccccc}
\hline & $\begin{array}{c}\text { Upper Torch Power, } \\
\mathrm{kW}\end{array}$ & $\begin{array}{c}\text { Modular Torch } \\
\text { Power, } \\
\mathrm{kW}\end{array}$ & $\begin{array}{c}\text { Total Hybrid Plasma } \\
\text { Power Input, } \\
\mathrm{kW}\end{array}$ & $\begin{array}{c}\text { Powder Feed Rate, } \\
\mathrm{lb} / \mathrm{hr}\end{array}$ \\
\hline 201 & 9.25 & 9.13 & $18.38(3.676)$ & 0.66 \\
202 & 12.52 & 10.80 & $23.32(4.664)$ & 0.66 \\
203 & 13.42 & 13.48 & $26.90(5.380)$ & 0.66 \\
204 & 13.60 & 16.50 & $30.10(6.020)$ & 0.66 \\
205 & 13.30 & 10.70 & $24.00(4.800)$ & 1.42 \\
\hline
\end{tabular}


Plasma instability had been observed during hybrid plasma operations. The plasma instabilities included fluctuations of the plasma plume length and the plasma plume's breaking up. These events were observed quite frequently during the powder synthesis runs. The plasma plume fluctuation and break up were captured in Figure 7. In the picture, the plasma is clearly seen breaking up into several minor red plumes. The minor plumes might be associated with particle

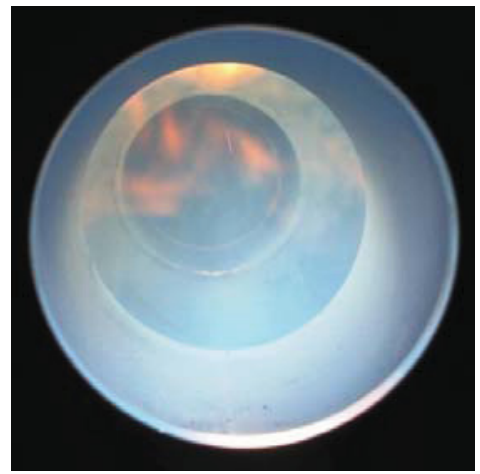

Figure 7. The arc root instability caused the plasma tail flame to fluctuate and breaks up.

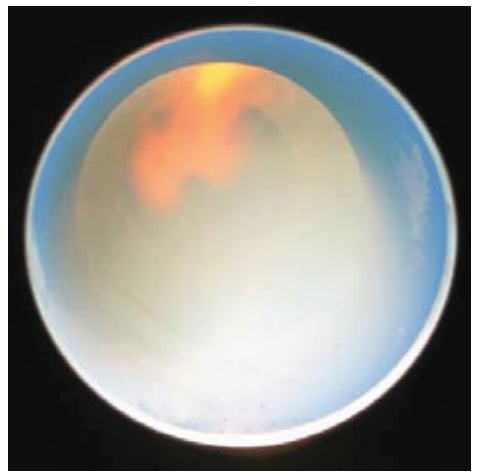

Figure 8 . With a stable arc-root attachment the plasma tail flame is more stable and extended. vapor. When this event occurred, the arc column moved back up into the arc channel. Sometimes the arc would extinguish and would restart by itself when powder feeding was turned off. When that failed, manual restart of the modular plasma unit would re-establish the hybrid plasma. The root cause of this instability was arc-root attachment instability. This phenomenon was caused by a number of factors. Normally, when the arc was rotating, it would display a shape similar to Figure 8. Under a very fast arc rotation the tail jet shape was tapered and elongated, and would appear stationary or steady. The arc rotational speed was governed by the magnitude of the arc current applied to the modular plasma unit when the plasma gas was not swirling. The arc rotation was effected by a self-generated internal magnetic field to pin the arc roots on the surface of the tungsten electrodes. A very special configuration of the arc current feed and return paths produced this self-generated, stabilizing internal magnetic field. Due to moving charge, the feed and return current paths also caused the arc root to rotate on the surface of the tungsten electrodes. In this bench-scale system, there was a limit to the magnitude of the applied current and, therefore, the arc rotation was not exceedingly fast.

However, if the plasma gas coming from the upstream plasma unit was also swirling, then the arc root rotation would be enhanced. The special configurations of arc current feed and return paths eliminated the use of external power supplies to generate external magnetic fields for arc rotation and stabilization. This invention reduced energy use by the hybrid plasma system for material productions compared to conventional plasma systems.

The motion of the arc roots on the surface of the electrodes is clearly evident. Particularly, on the surface of cathode, the evidence of arc root rotation is very strong. The attachment of the cathodic arc root was constricted to a small spot. The arc root temperature was very high, significantly higher than the melting temperature of tungsten, $3400^{\circ} \mathrm{C}$. The arc root caused surface melting of tungsten and formed molten droplets. The molten tungsten formed elongated shapes due to the drag motion of the rotating arc root. The evidence of cathode arc-root rotation is shown in Figures 9 and 10. Figure 9 shows the modular cathode assembly and the molten droplets formed on the surface of the tungsten ring electrode. Figure 10 is an enlarged view of the tungsten cathode ring surface and shows the roughness due to arc-root dragging of the molten drop during rotation. The elongated shape of the molten droplets indicated the direction of arc rotation. The molten drops formation is indicative of tungsten surface temperature exceeding $3400^{\circ} \mathrm{C}$. Figure 11 shows the modular anode assembly with the smoother surface of the tungsten electrode. The anode arc-root attachment spot was much more diffused, and the heat flux loading per unit surface significantly lower when compared to the cathode. The surface melting of the tungsten anode was much less and, thus, retained a smoother surface. 


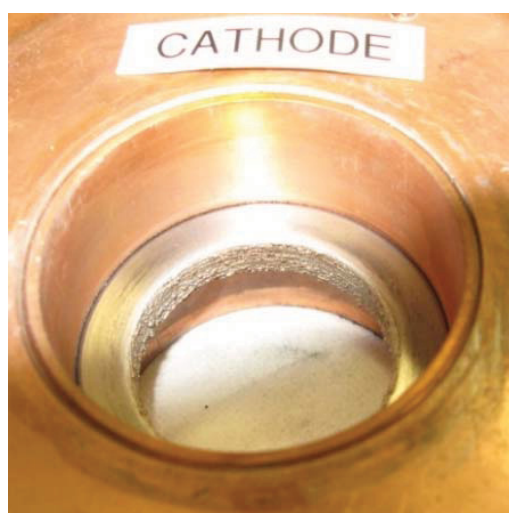

Figure 9. Modular cathode assembly shows the molten droplets formed on the surface of the tungsten electrode.

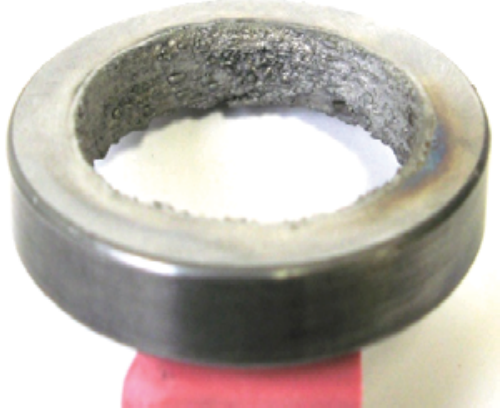

Figure 10. Enlarged view of the tungsten cathode surface and the elongated shape of the molten drop indicating the direction of arc rotation.

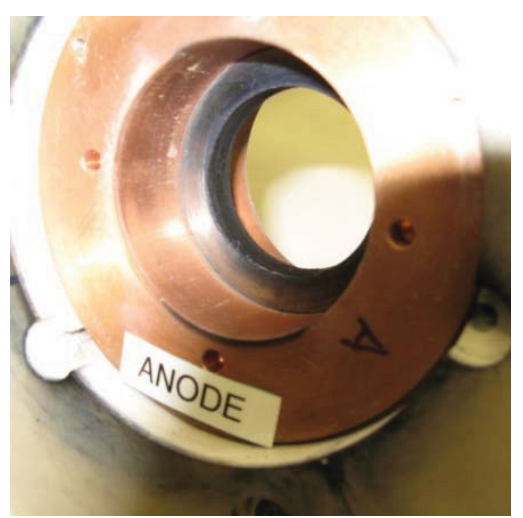

Figure 11. The modular anode assembly shows a much smoother surface on the tungsten ring electrode. 


\section{HYBRID PLASMA SYSTEM FAILURE}

When the modular plasma system was new or newly refurbished, it could self-start after the upstream plasma was established and would run smoothly. After repeated use a problem surfaced. The problem was associated with the modular torch, which went out prematurely and caused the test run to shut down. Frequently, the modular plasma torch would restart after engaging the start-button. At times, the modular plasma torch would not restart, and a high-frequency arc starter would need to be engaged to start the modular plasma torch unit. Later, after repeated use of the system, the modular plasma torch would go out during a run and could not reestablish the hybrid plasma, even with the assistance of the high-frequency arc starter. The system was disassembled and every component was thoroughly clean and reconditioned. After the system was reassembled, testing resumed. The system would operate smoothly for a while, after which the problem resurfaced. Cleaning and reconditioning operations for all components were carried out more often to maintain the hybrid plasma system in an operable condition. However, the operability of the hybrid plasma system became more erratic and broke down frequently. Finally, the modular plasma torch would not ignite even with the continuous engagement of the high-frequency arc starter while operating the upstream plasma torch simultaneously. Many different methods were tried, including operating the upstream plasma at maximum power, to get the modular plasma system going again. However, all attempts were unsuccessful. The complete system was dismantled and reassembled numerous times to look for flaws and defects in components and materials. Nothing out of the ordinary was observed.

This fact puzzled the research team for a long while, and research progress came to a complete stand still. During one re-examination of all disassembled components the modular cathode was accidentally bumped hard again the bench top. The tungsten ring cathode became slightly slanted inside the copper electrode housing. Attempts to push the cathode against the ring electrode completely dislodged the cathode from its housing. This was an extremely surprising development because the ring electrode was designed to fit tightly against the copper electrode housing wall. This tight fitting provided electrical continuity across the entire modular electrode and thus sustained arc operation. The original design of the modular cathode using a press fitted tungsten ring electrode is shown in Figure 12. After a dimension check, it became clear that both the tungsten ring cathode and the copper housing had a minute dimension change after several uses. Once the tungsten ring was reinstalled inside the copper housing, an electrical measurement was taken, and the result showed extremely high resistance across the interface. The tungsten ring electrode became a

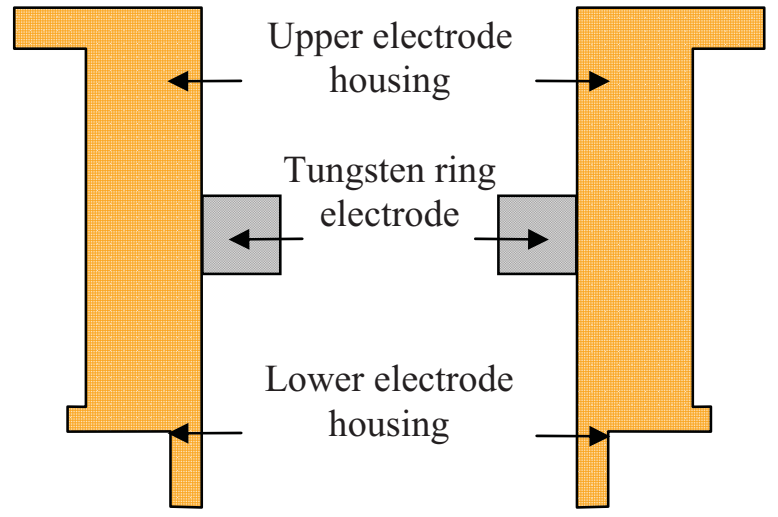

Figure 12. The original modular electrode assembly used a press fitted tungsten ring electrode. loose fit in the electrode housing. Loose contact increased the contact resistance significantly and also produced poor electrical continuity across the interface. In the initial press fit of the tungsten ring into the copper housing, a thin skin of copper may have been scraped out. This probably planted the component dimension changes down the road. Temperature cycling of the metal components during repeated operations of the hybrid plasma system further exacerbated the dimension changes between copper and tungsten. In operation, the modular plasma unit was preheated by the upstream plasma before hybrid arc ignition. In preheating, the copper housing for the modular cathode might have expanded more than the tungsten ring electrode. The expansion caused the complete loss of physical contact between the copper housing and tungsten ring electrode. This could explain the electrical failure of the modular plasma unit due to dimension changes of the modular cathode components. However, this problem did not occur to 
the modular anode.

Since this press-fitted electrode design would fail after a rather limited number of runs. A new design for the modular electrode was necessary to overcome this problem. The redesign would make the electrode housing and the ring electrode into a single integrated unit. The new design, showed in Figure 13, integrated the $\mathrm{W}$ ring electrode into the copper housing as a single unit and bonded by high temperature brazing methods.

In the old design, the tungsten ring electrode was indirectly cooled by contact through the copper housing. This new design has intricate groves and exposes the tungsten ring electrode directly to water cooling. The tungsten ring electrodes are very expensive and must be custom made. An outside vendor was chosen to fabricate the tungsten ring electrodes. The new design was sent to a vendor for custom manufacturing of the tungsten electrodes, and after eight weeks, the electrodes were delivered. INL crafts attempted many times to braze the tungsten ring electrode into the upper and lower copper sections of the electrode assembly. However, the braze joint would leak cooling water severely. Repeated brazing did not rectify the problem. The high-temperature brazing operations also warped the copper housing components, the whole modular electrode unit was out of alignment, and the modular electrode unit could not be assembled. During hightemperature heating to retrieve the tungsten ring electrodes from the damaged housings, one of the tungsten ring fractured. The other also showed significant corrosion damage from the brazing flux agent. Figure 14 shows the damaged and fractured tungsten ring electrodes. Braze joining of the electrode components was not successful, and an alternative route must be found to join the electrode assembly components. A mechanical joining method was developed to mate the components together to form the modular electrodes. New copper electrode housing components were fabricated to receive the tungsten ring electrodes. The tungsten ring electrode was redesigned for mechanical joining. Three sections comprised of the new modular electrode design. The tungsten ring electrode was sandwiched between the upper and lower copper electrode

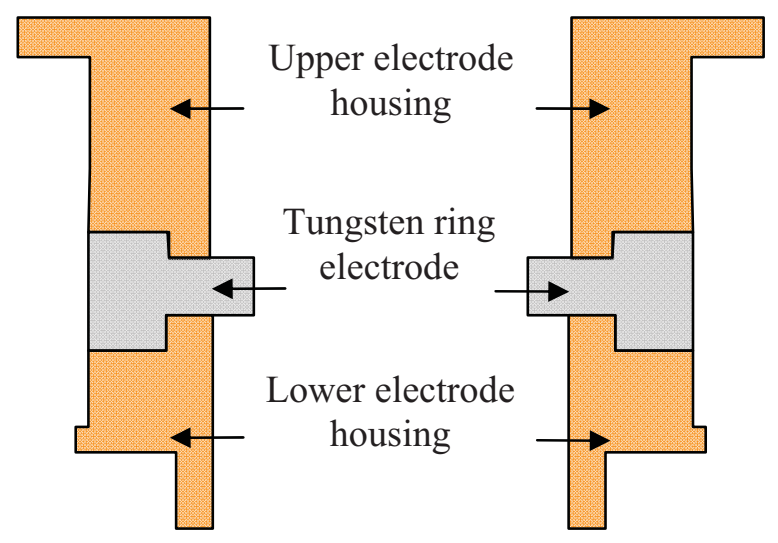

Figure 13. The new configuration is a segmented modular electrode assembly. Both anode and cathode use the same design.

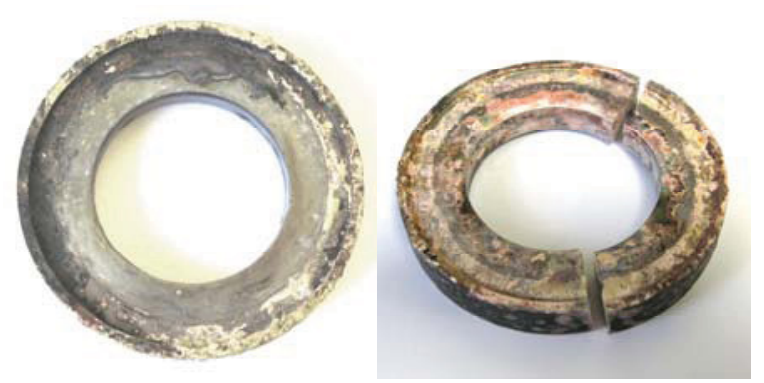

Figure 14. The left photo shows the anode, and the right, the fractured cathode during the high temperature brazing process.

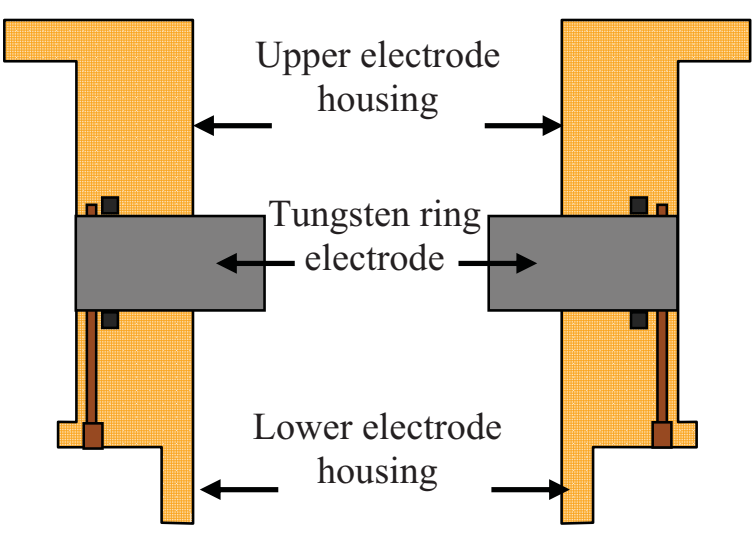

Figure 15. The modified new design for the modular electrode assembly used a mechanical mating joint. housing units. The sections were joined by long thin bolts and sealed by compression o-rings. The tungsten ring electrodes were cooled by high pressure water directly. The modified new design is shown in Figure 15. The new tungsten ring electrode design was sent to the vendor for fabrication. 


\section{HYBRID PLASMA SYSTEM POWER CYCLING TEST}

While waiting for the new tungsten electrodes for the GEN V system run characteristics, $I$ and $V$, were studies for GEN IV. The $I$ and $V$ character for each generation of the hybrid plasma should be very similar, if not identical, because only the arc channel diameter was changed to produce a longer residence time. The hybrid plasma run characteristics were monitored real time to determine the system performance and efficiency.

Any problem developed with the system during a run would be tracked, analyzed, and resolved. Runs 206 through 208 were power-cycling tests for the modular hybrid plasma system. These tests were performed without powder injection. Figure 16 through Figure1 8 plotted the real-time current and voltage data for the upstream plasma unit and the downstream modular plasma system, and the power of each unit was calculated from the data. The data showed one interesting phenomenon.

In test 206, shown in Figure 16, the current of the upstream plasma torch was set at 400 amps initially. Then the modular plasma torch current was ramped from 100 amps to 165 amps, 235 amps and 270 amps. During current ramping, the modular torch voltage decreased steadily. The modular plasma torch voltage, shown in Figure 16 as a series of red triangles, clearly indicated that. The data seem to indicate that ionized species from upstream plasma help to reduce the voltage requirement of the downstream plasma system. The stability of the modular plasma also increased. In a second test, the upstream plasma-torch current was increased to $600 \mathrm{amps}$, and then the modular torch current was ramped

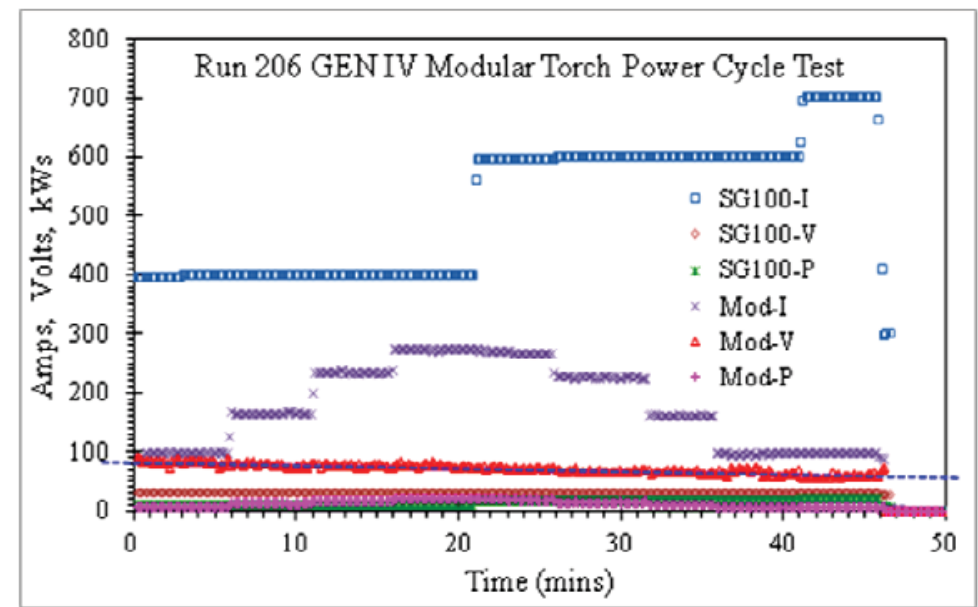

Figure 16. Run 206 GEN IV modular hybrid plasma power cycle test with both upstream and modular torches varying.

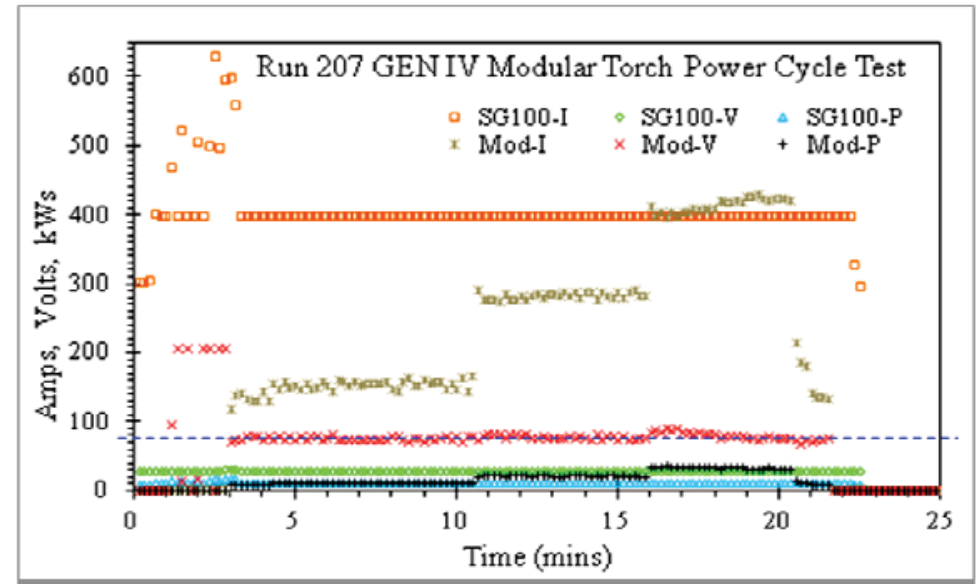

Figure 17. Run 207 GEN IV modular hybrid plasma power cycle test with constant upstream plasma power.

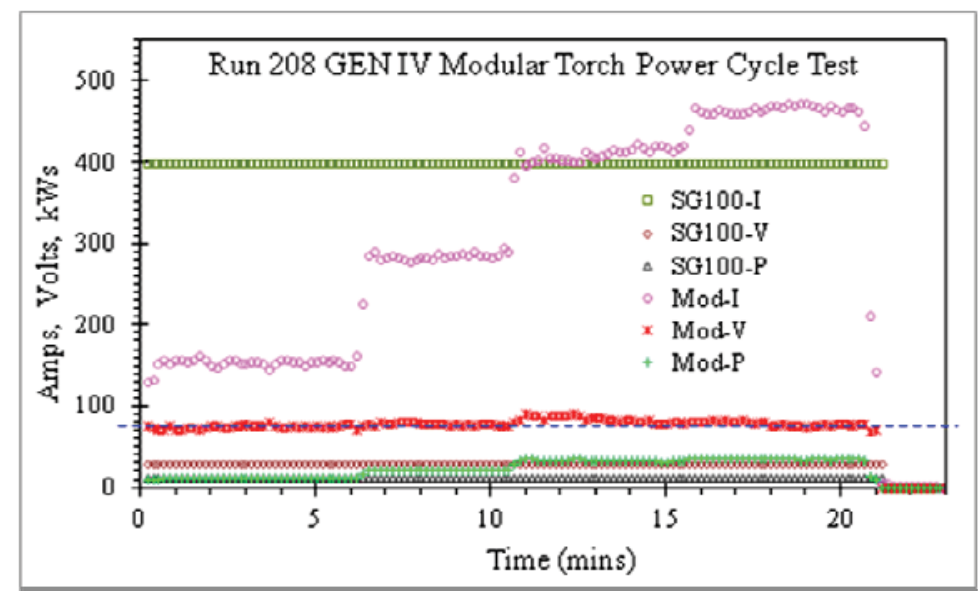

Figure 18. Run 208 GEN IV modular hybrid plasma power cycle test with higher varying modular plasma power. 
down in reverse order. The magnitude of the modular torch voltage decrease was even greater. When the modular plasma torch current was at $100 \mathrm{amps}$, the upstream plasma torch current was ramped up to 700 amps. The modular torch voltage continued to decrease to $55 \mathrm{~V}$. The blue dotted line clearly showed the decreasing trend of the modular plasma torch voltage. Compared to the initial voltage ( $80 \mathrm{~V}$, indicated by the black solid line in Figure 16) the modular hybrid plasma voltage decreased by as much as $31.25 \%$. The voltage drop was quite significant and indicated a reduction in power consumption by the modular plasma unit. This was a power dump effect from the upstream plasma. When the upstream plasma system operated at higher power levels, it provided higher ionization of the plasma and thus reduced the voltage requirement of the modular plasma system. This shows that the modular plasma torch was strongly influenced by the ionization of the upstream plasma.

In Test 207 (Figure 17) and Test 208 (Figure 18), the upstream plasma was kept as a low operating power $(12.8 \mathrm{~kW})$. The upstream plasma torch current was set at 400 amps and remained constant for the duration of the test. The modular plasma current varied from 155 to 465 amps. Below 400 amps there was no change in the modular plasma voltage. When the modular plasma current increased to $400 \mathrm{amps}$, the voltage rose 15 volts (black dotted lines). Then the voltage drifted back down to the original value. It showed the upstream plasma torch would have no effect on power reduction in the downstream modular plasma unit if it was operated at constant low power. This implied a combination of high-power upstream plasma and low-power downstream modular plasma to produce the energy-efficient, large and uniform high-temperature zone for materials processing. During these tests, the inlet and outlet temperatures and cooling flow rates for all system subcomponents were also monitored real time. 


\section{TUNGSTEN OXIDE SYNTHESIS COMPARISON}

Several tungsten oxide injection runs were carried out using only the conventional upstream plasma torch in the hybrid plasma system to establish the baseline differences for feed-material vaporization between a conventional plasma torch and a modular hybrid plasma system. These runs, Tests 210 to Test 212, were conducted under different input-power conditions to assess the size of the particles obtained after vaporization. The upstream plasma torch power was $12 \mathrm{~kW}(400 \mathrm{~A}, 30 \mathrm{~V})$ for Test 210, $15 \mathrm{~kW}(500 \mathrm{~A}, 30 \mathrm{~V})$ for Test 211 , and $18 \mathrm{~kW}(600 \mathrm{~A}, 30 \mathrm{~A})$ for Test 212. Figure 19 shows the typical $\mathrm{X}$-ray diffraction analysis of the products for these tungsten oxide vaporization runs. All products showed identical crystalline structure. Three crystalline phases; monoclinic, triclinic, and orthorhombic, were matched by X-ray diffraction analysis. From X-ray diffraction analysis, the product contained both the monoclinic and triclinic phases. All three Test run products showed significant peak broadening compared to the feed material. This indicated a significant particle size reduction after the plasma vaporization. It was more interesting to compare the size reduction between these runs. The width of the diffraction peak at half maximum was a measure of the average grain size. The wider the peak at half maximum, the smaller the average grain size would be. Figure 20 shows the average grain size comparison between these runs. Test 212 had the highest plasma current at $600 \mathrm{~A}$, and the joule heating effect was directly related to $\mathrm{I}^{2}$. At $600 \mathrm{amps}$, this test had the highest heating power for the plasma gas among the 3 tests. The highest heating power resulted in the highest vaporization of the feed. It is evident in Figure 20 that the peak broadening between $32^{\circ}$ and $35.5^{\circ}$ (see Figure20, brown dash box) due to smaller grain size was the largest in Test 212. It was clear from these

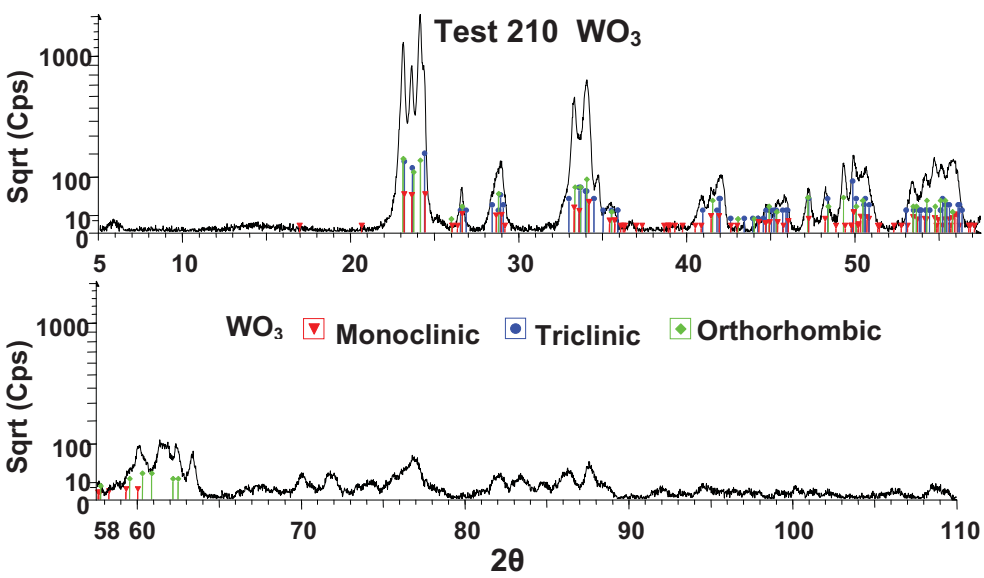

Figure 19. X-ray diffraction analysis of Test 210 and the run conditions were $400 \mathrm{~A}$ and $30 \mathrm{~V}$. results that the product formed in Test 212 had the smallest average grain size. Figure 21 includes the starting $\mathrm{WO}_{3}$ for the average grain size comparisons. It is apparent that the starting $\mathrm{WO}_{3}$ was quite a bit larger than the processed materials. The average particle diameter could be calculated from the width of the diffraction peak at $1 / 2$ the maximum diffraction intensity and is given by the equation $D=0.9 \lambda / B \cos \theta_{B}$. where $B$ is the peak width at half maximum intensity and $\theta_{B}$ is the diffraction angle at maximum intensity. The results will be used for comparison with the results obtained from the hybrid system in future runs. 


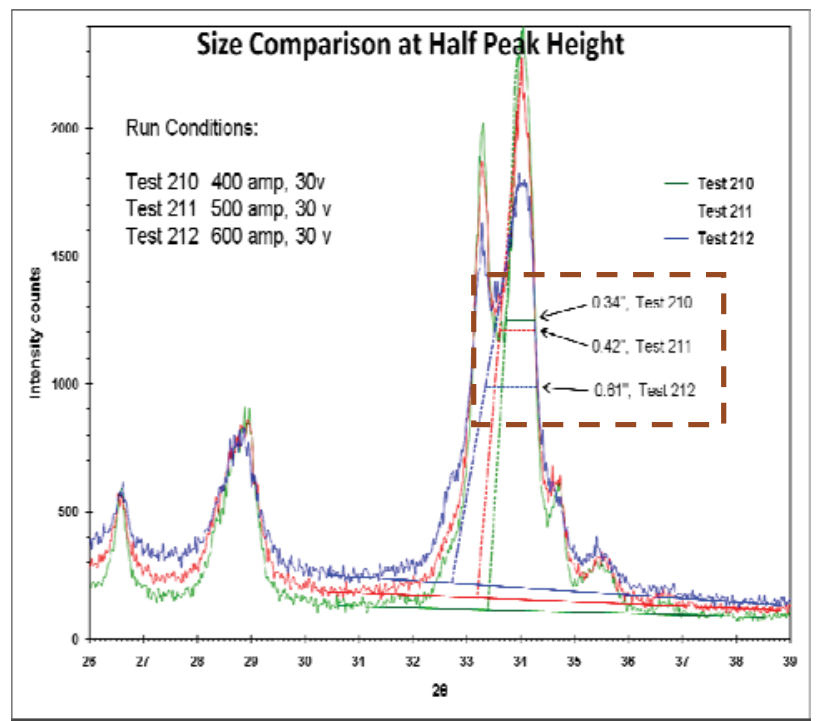

Figure 20. X-ray particle size analysis using peak width at half peak maxima for tests 210 to 212 .

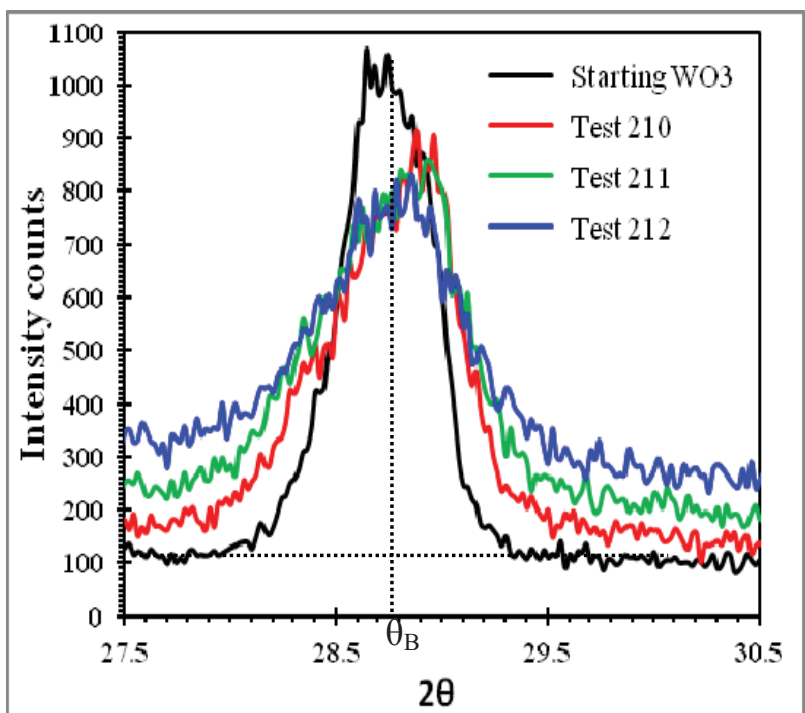

Figure 21. Average particle size comparison between starting $\mathrm{WO}_{3}$ and runs 210 to 212 . 


\section{STAINLESS STEEL ELECTRODES TESTING}

While waiting for the second set of replacement tungsten ring electrodes to be delivered by the vendor, stainless steel ring electrodes that used the new mechanical mating method to form the electrode assembly were used in the hybrid plasma reactor to test their operability as an alternative electrode material. If stainless steel electrodes could be used instead of tungsten, both the material cost and electrodes acquisition time would be reduced by as much as $90 \%$. Initial tests of stainless steel ring electrodes in the hybrid plasma system met with many difficulties. The modular plasma system would not ignite under many test conditions. Finally, after many failures, the minimum combinations of power requirements between the upstream plasma and the downstream modular unit to ignite the hybrid plasma were identified. Figure 22, run 214, shows the real-time run data for the hybrid plasma system using the stainless steel ring electrodes. The upstream plasma must use a 500A minimum current to ignite the downstream modular plasma. The modular plasma unit operated at about $75 \mathrm{~V}$, and the minimum current required to sustain the hybrid plasma was $155 \mathrm{~A}$. The modular plasma current was stepped from $155 \mathrm{~A}$ to 240 A to observe system operation characteristics. The upstream plasma current was also increased from $500 \mathrm{~A}$ to $580 \mathrm{~A}$ to observe the response of the modular plasma to the upstream plasma power increase. There was the same general trend of a gradual modular plasma voltage decrease

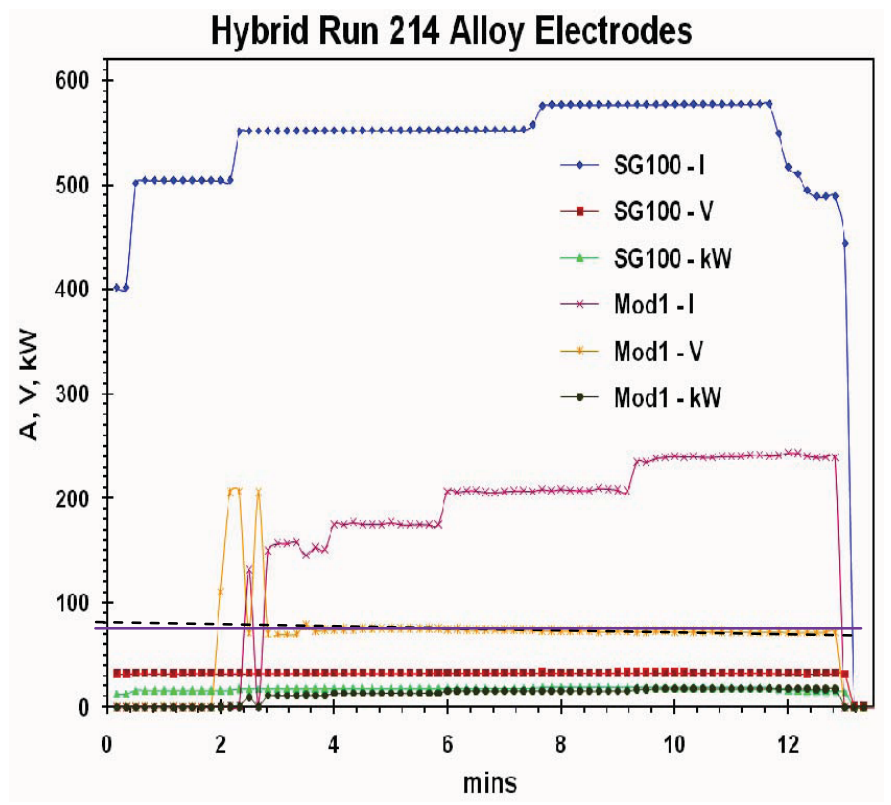

Figure 22. Real time data for hybrid run 214 using stainless steel electrodes. when the upstream plasma power increased. The modular plasma voltage dropped by about 5 volts, a $7 \%$ drop. The observed voltage drop for the modular plasma unit using the stainless steel electrodes was not as impressive as the tungsten electrode system. However, the observed characteristics of power reduction for the modular hybrid plasma unit were the same. The test results indicated that the stainless steel could be used as an alternative electrode material in the hybrid system. More tests will be needed in the future with other metal electrodes in the hybrid system as a substitution for tungsten.

The mechanical mating of the stainless steel ring electrode to the upper and lower copper electrode housing assembly was successful. No leaking water was detected in the electrode units during the system operational test. This modified new electrode design with mechanical mating offered one additional benefit that was not expected in the original research plan. This new design allowed for easy swapping of electrodes for different electrode-materials testing. This modified new electrode design will provide the opportunity of electrode-materials development for oxidizing and reducing plasma gas environment applications. 
The condition of the stainless steel electrodes was compared to the tungsten electrodes for degradation after the tests. The tungsten electrodes used the old design of tight-contact cooling. The stainless steel electrodes use the new design with mechanical mating. Figure 23 shows the appearances of the tungsten and stainless steel cathodes. The cathode arc-root attachment was very constricted, and the heat flux loading was very high on the surface of the cathodes. The tungsten showed localized surface melting with arc rotation streaks (see Figure 23a). The erosion on the tungsten cathode was not significant. The condition of the stainless steel cathode is shown in Figure 23b. The stainless steel cathode showed higher surface melting. The melting and erosion of the cathode was due to (i) the lower melting temperature of stainless steel, and (ii) a suboptimal cooling design. With a better cooling design in the cathode ring, the erosion of the stainless steel should decrease. Figure 24 shows the conditions of the tungsten and stainless steel anodes after the tests. Both the tungsten and the
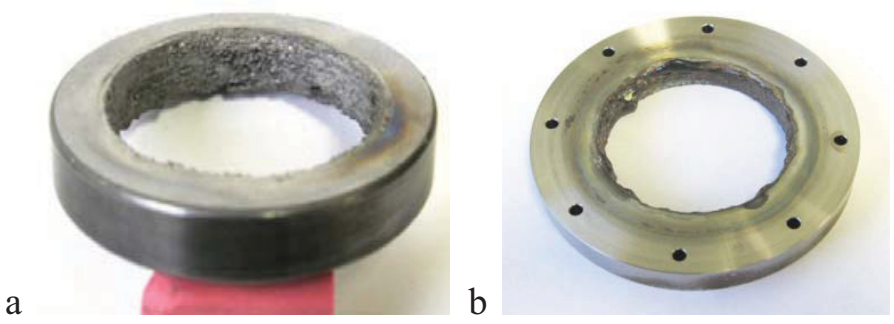

Figure 23. Condition of the cathodes after run, (a) tungsten cathode showed the arc rotation streaks on the surface, and (b) SS cathode shows significantly more erosion because of lower melting temperature.
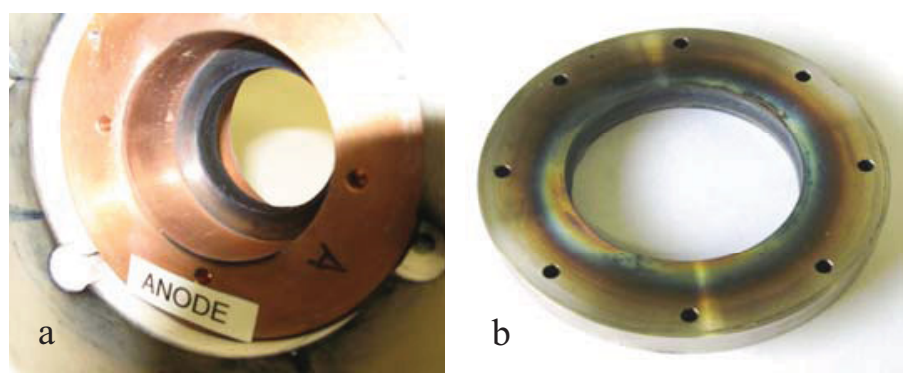

Figure 24. Condition of the tungsten anode (a) and SS anode (b) after tests, both anodes showed no sign of erosions because of diffused arc attachment and rotation of the arc roots. stainless anodes, as shown in Figure 24 a and b, show no signs of erosion. This is due to a significantly diffused arc-root attachment mode on the anode. Diffused arc-root attachment reduces the heat flux loading onto the anode surface. 


\section{TUNGSTEN OXIDE SYNTHESIS WITH NEW MODULAR ELECTRODE DESIGN}

The replacement tungsten electrodes arrived, and the copper electrode housings were modified to receive the electrodes for mechanical mating. $\mathrm{WO}_{3}$ production runs were made with the hybrid reactor using the upstream plasma torch at various power levels to set baselines for comparison. Later, hybrid runs were made to compare the particle size produced. For most of the runs, the upstream plasma was kept at a constant power level to assess the influence of the downstream hybrid plasma on the particles produced. Figure 25 shows the X-ray-diffraction particlesize analysis upon startup and with nonhybrid and hybrid plasma processed $\mathrm{WO}_{3}$. The width of the peak at half maximum was indicative of the average particle size. A wide half maximum indicated average small grain size. Figure 25 reveals that $\mathrm{WO}_{3}$ particles produced with the hybrid plasma are much smaller

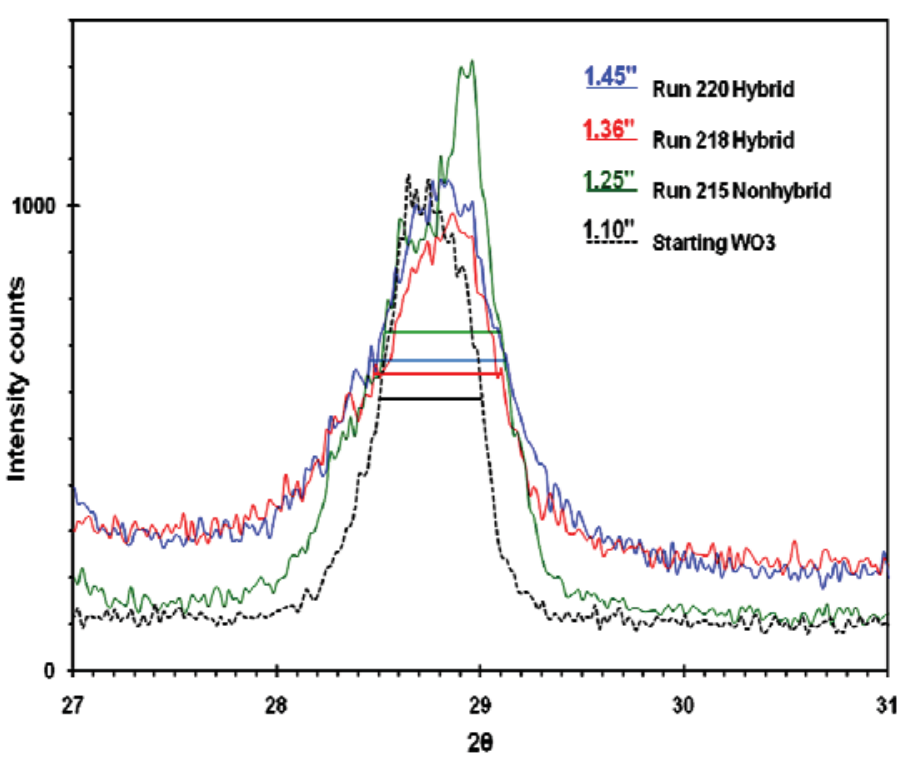

Figure 25. Particle size comparison between starting $\mathrm{WO}_{3}$, nonhybrid plasma processed $\mathrm{WO}_{3}$, and hybrid plasma processed $\mathrm{WO}_{3}$. than nonhybrid plasma produced $\mathrm{WO}_{3}$ particles and the starting $\mathrm{WO}_{3}$ particles.

The real-time run data for hybrid runs 218 and 220 are shown in Figure 26. In hybrid run 218, the open voltage of the modular plasma unit was set at $200 \mathrm{~V}$. This setting allows the power supply to draw a maximum current of 300A. The new tungsten ring electrodes had not been broken-in and could not start the modular arc, even using the high-frequency arc starter. The front end of the real-time data showed no modular hybrid arc started until the upstream plasma was operated at 600A. Below 200A the modular unit
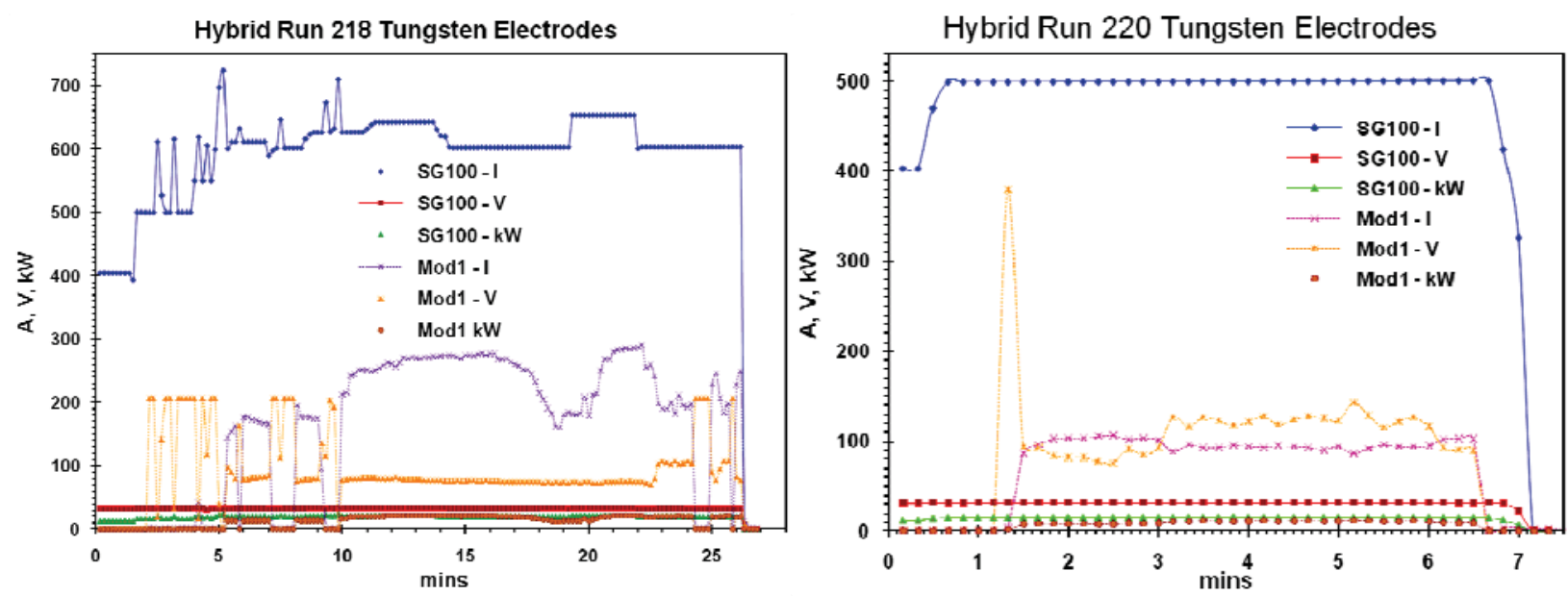

Figure 26. Real time data for hybrid runs 218 and 220, with tungsten electrodes for $\mathrm{WO}_{3}$ processing. Run 218 ran with $200 \mathrm{~V}$ open voltage for the modular unit. Run 220 ran with $400 \mathrm{~V}$ open voltage for the modular unit. 
could not sustain continuous powder feeding, and the arc extinguished often. Powder feeding was stopped for 5 minutes after an intermittent run, and the modular unit was tested for sustained power run conditions. The minimum modular current the unit required to operate was $275 \mathrm{~A}$ to sustain the hybrid plasma. The total combined input power for the hybrid run was $40 \mathrm{~kW}$. In hybrid run 220, the open voltage of the power supply for the modular unit was set to $400 \mathrm{~V}$. This setting limited the power supply to draw a maximum current of $150 \mathrm{~A}$, but allowed a higher voltage to sustain ionization. Under the higher open voltage, the modular unit self started without using a high-frequency arc starter. The arc current was set 100A, and the arc voltage was about $125 \mathrm{~V}$. The run was smooth, and the upstream plasma was maintained at 500A. The total combined power for hybrid run 220 was $28 \mathrm{~kW}$, which was $70 \%$ of the total input power of hybrid run 218 . Since the upstream plasma power for runs 215 and 220 were identical, the particle size of hybrid run 220 would be influenced by the downstream modular plasma.

Figure 25 confirms that the average particle size of run 220 was indeed much smaller than run 215, as well as of the starting $\mathrm{WO}_{3}$. Figure 27 captures the $\mathrm{WO}_{3}$ nanoparticle fumes leaving the plasma tail plume in hybrid run 220. The nanoparticles appeared as a slight bluish gray haze flowing inside the reactor. The bluish gray color was the result of a slight decomposition of

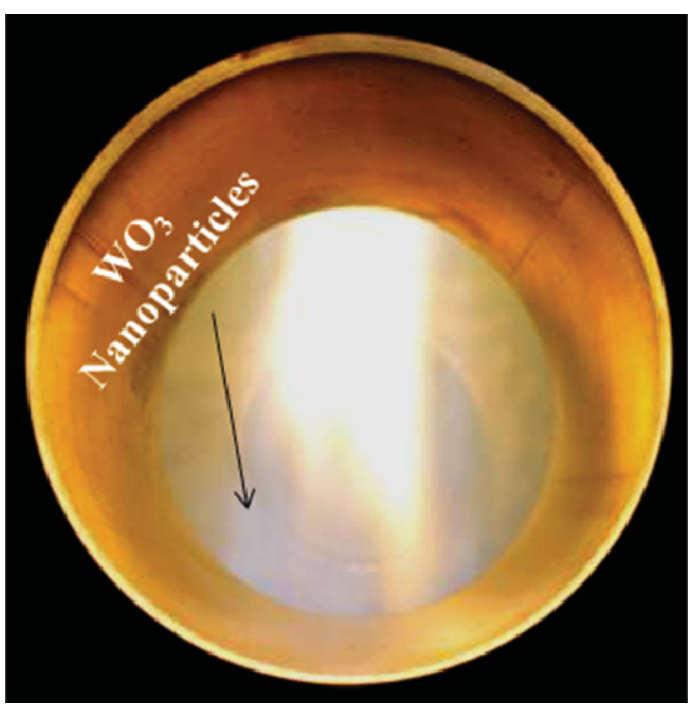

Figure 27. In hybrid run $220 \mathrm{WO}_{3}$ nanoparticle fumes are seen leaving the hybrid plasma tail flame. $\mathrm{WO}_{3}$ to $\mathrm{WO}_{3-\mathrm{x}}$ by the carbon insulation inside the arc channel.

Table 2 shows a summary of several selected runs of the hybrid plasma reactor. Runs 213-214 tested the feasibility of using stainless steel as an alternative electrode material in the hybrid plasma reactor system. Runs 215-217 were the baseline tests for particle size with the upstream plasma torch operated at different power levels. Runs 218-221 were the hybrid plasma powder production tests using the mechanical mating design for the modular tungsten electrodes.

A series of runs was also performed to compare $\mathrm{WO}_{3}$ particle size produced by a conventional plasma reactor, the hybrid reactor without the modular unit operating, and the full modular hybrid plasma reactor. The discussion below describes the specific selected results of runs 212, 216 and 225. 
Table 2. Run summary of the modular hybrid plasma system.

\begin{tabular}{|c|c|c|c|}
\hline Run & Top plasma torch & Modular plasma torch & Remarks \\
\hline 213 & Run data deleted & Run data deleted & $\begin{array}{l}\text { Stainless steel modular electrodes } \\
\text { difficult to start; had to operate the } \\
\text { upstream plasma at a high current to } \\
\text { start the modular unit }\end{array}$ \\
\hline 214 & Run data deleted & Run data deleted & $\begin{array}{l}\text { Stainless steel modular electrodes } \\
\text { difficult to start; after starting, the } \\
\text { modular unit needed to run at high } \\
\text { power setting to sustain a long run; } \\
\text { stainless steel was a viable alternative } \\
\text { electrode to be used in the system }\end{array}$ \\
\hline 215 & Run data deleted & $\begin{array}{l}\text { Baseline setting for } \mathrm{WO}_{3} \\
\text { processing in MHPR } \\
\text { configuration; }\end{array}$ & $\begin{array}{l}\text { Stainless steel modular electrodes; no } \\
\text { modular torch operation }\end{array}$ \\
\hline 216 & Run data deleted & $\begin{array}{l}\text { Baseline setting for } \mathrm{WO}_{3} \\
\text { processing in MHPR } \\
\text { configuration; }\end{array}$ & $\begin{array}{l}\text { Stainless steel modular electrodes; no } \\
\text { modular torch operation }\end{array}$ \\
\hline 217 & Run data deleted & $\begin{array}{l}\text { Baseline setting for } \mathrm{WO}_{3} \\
\text { processing in MHPR } \\
\text { configuration; }\end{array}$ & $\begin{array}{l}\text { Stainless steel modular electrodes; no } \\
\text { modular torch operation }\end{array}$ \\
\hline 218 & Run data deleted & $\begin{array}{l}\text { Open voltage } 200 \mathrm{~V} \text {; voltage } \\
\text { mostly operated at } 76 \mathrm{~V} \text {; current } \\
\text { mostly operated at } 270 \mathrm{~A} \text {; power } \\
\text { mostly operated at } 20.00 \mathrm{~kW}\end{array}$ & $\begin{array}{l}\text { Hybrid operation; mechanical mating } \\
\text { design for tungsten ring electrodes; } \\
\mathrm{WO}_{3} \text { processing; modular plasma unit } \\
\text { kept going out, initially, when the } \\
\text { current was set below } 200 \mathrm{~A} \text {; the } \\
\text { operation was smooth at high currents }\end{array}$ \\
\hline 219 & Run data deleted & Run data deleted & $\begin{array}{l}\text { Hybrid operation; mechanical mating } \\
\text { design for tungsten ring electrodes; } \\
\mathrm{WO}_{3} \text { processing; rerun } 218 \text {; modular } \\
\text { plasma unit kept going out at powder } \\
\text { feeding }\end{array}$ \\
\hline 220 & Run data deleted & $\begin{array}{l}\text { Open voltage } 400 \mathrm{~V} \text {; average } \\
\text { current } 93.0 \mathrm{~A} \text {; average voltage } \\
123 \mathrm{~V} \text {; average power } 11.56 \\
\mathrm{~kW} \text {; operation very steady }\end{array}$ & $\begin{array}{l}\text { Hybrid operation; mechanical mating } \\
\text { design for tungsten ring electrode; run } \\
\text { was very steady for } \mathrm{WO}_{3} \text { processing }\end{array}$ \\
\hline 221 & Run data deleted & Run data deleted & $\begin{array}{l}\text { Hybrid operation was very steady } \\
\text { except the arc extinguished } 3 \text { times } \\
\text { during powder feeding; the arc } \\
\text { reestablished itself after powder } \\
\text { feeding was momentarily interrupted; } \\
\text { mechanical mating design for tungsten } \\
\text { ring electrodes; } \mathrm{WO}_{3} \text { processing }\end{array}$ \\
\hline
\end{tabular}


Table 3 summarizes the experimental conditions and volume change for the same mass weight of $\mathrm{WO}_{3}$ feed material in these runs. Run 212 was performed with a conventional plasma torch reactor. The plasma torch was identical to the upstream plasma unit used in the modular hybrid plasma reactor. Only one injection port was equipped with this conventional torch reactor. The powder feed rate and the carrygas volume were cut by half. Therefore, the cooling of the plasma by injected particles and carry gas was less. Run 216 was performed in the hybrid plasma reactor configuration. However, only the upstream plasma torch was utilized, and the downstream modular plasma unit was not turned on. The plasma power for runs 212 and 216 was the same. However, the plasma in run 216 experienced twice the cooling effect due to doubling the powder feed rate as well as the atomizing gas flow rate. Therefore, the processing temperature was expected to be the lowest in run 216. The differences between these two configurations were the length of the processing zone and a plasma tail plume quenching zone in the hybrid plasma reactor. The conventional plasma reactor had 6 in. of processing zone, while the modular hybrid plasma reactor had a processing zone of more than 16 in. long. Compared to the $\mathrm{WO}_{3}$ feed, the product in run 212 had a volume increase of 6.9 times while run 216 had a volume increase of 6.1 times. The particle size for these two runs were comparable, and a longer processing zone in run 216 offset a lower temperature in the system. The product obtained from a full hybrid run, run 225, was compared to these two runs. In the hybrid plasma run, the modular plasma unit was turned on, and it reheated the plasma gas from the upstream unit to high temperatures. The average plasma-applied power was $33.6 \mathrm{~kW}$. The powder volume in run 225 increased to 10.2 times when compared to the feed powder. The particle size in run 225 was significantly reduced.

Table 3. Volume change comparison for feed and plasma processed $\mathrm{WO}_{3}$ particles using different plasma system configurations.

\begin{tabular}{|c|l|}
212 & $\begin{array}{l}\text { Conventional plasma reactor } \\
\text { Powder feed rate was } 0.25 \mathrm{lb} / \mathrm{hr} \text {, and only } 1 \text { powder injection port was used in the conventional } \\
\text { plasma reactor. Plasma torch applied power was } 18 \mathrm{~kW} \text {. The processed powder volume } \\
\text { increased } \sim 6.9 \times \text { when compared to the same mass weight of the feed material. }\end{array}$ \\
\hline 216 & $\begin{array}{l}\text { Modular hybrid plasma reactor running in the non-hybrid mode } \\
\text { Powder production in the modular hybrid plasma system used the upstream plasma torch only. } \\
\text { Upstream plasma torch applied power was } 18.2 \mathrm{~kW} \text {. Powder feed rate was } 0.50 \mathrm{lb} / \mathrm{hr} \text {, and } 2 \\
\text { injection ports were used. The powder loading was twice that of Test } 212 . \text { The modular plasma } \\
\text { unit was not operated for this run. The process powder volume increased } \sim 6.1 \times \text { when compared } \\
\text { to the same mass weight of the feed powder. }\end{array}$ \\
\hline 225 & $\begin{array}{l}\text { Modular hybrid plasma reactor system running in the full hybrid mode } \\
\text { Powder production used the full hybrid plasma operation mode. Powder feed rate was } 0.50 \mathrm{lb} / \mathrm{hr}, \\
\text { and } 2 \text { injection ports were used. The powder loading was twice that of Test } 212 . \text { Average plasma } \\
\text { applied power was about } 33.6 \mathrm{~kW} \text {. Powder volume increased } \sim 10.2 \times \text { compared to the same mass } \\
\text { weight of the feed material. }\end{array}$ \\
\hline
\end{tabular}


Figure 28 shows the powder volume change for runs 212, 216 and 225 when compared to the tungsten oxide feed powder. The $\mathrm{WO}_{3}$ feed mass was $0.950 \mathrm{gm}$. The volume increase for run 212 was 6.9 times, 6.1 times for run 216, and 10.2 times for run 225. All these powders had equal mass weight. There were some color changes in these powders, and the change was caused by tungsten sub-oxide formation. Stoichiometric $\mathrm{WO}_{3}$ was yellow, and any deviation from this composition will cause a color change. The color could change from yellow $\left(\mathrm{WO}_{3}\right)$ to dark blue $\left(\mathrm{WO}_{2.72}\right)$ and was dependent on the deficiency in oxygen compositions. T212 had a bright blue color, and the oxygen deficiency was quite high because a graphite tube was used as the reaction zone in the conventional plasma reactor. Both T216 and T225 were very slightly greenish yellow, which indicates the composition is quite close to $\mathrm{WO}_{3}$. Because of this polyoxostate, tungsten oxides are electrochromic, and this oxide was the main
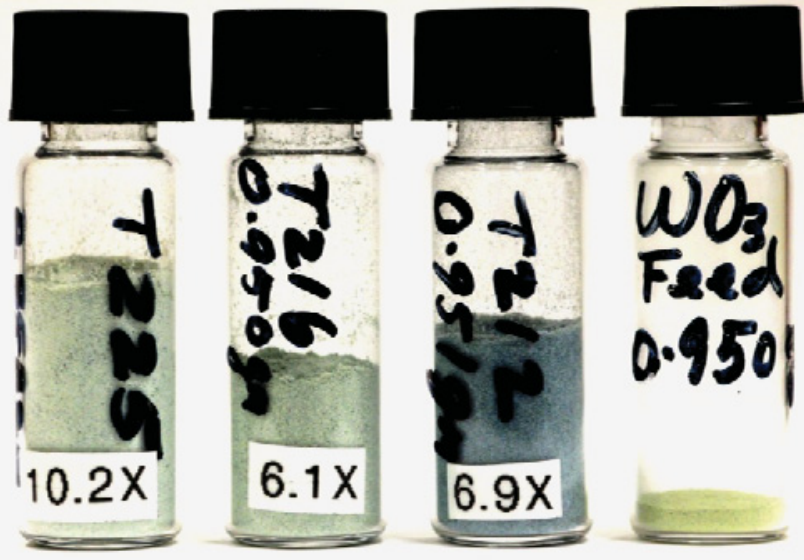

Figure 28. Volume change comparison for feed and plasma processed $\mathrm{WO}_{3}$ powders using different plasma reactor configurations. T212 used a conventional plasma torch, T216 used the upstream plasma torch only in the hybrid plasma reactor configuration, and T225 used the full hybrid plasma reactor operation mode.

chemical used in the production of

electrochromic windows or smart glass.

After the redesign of the modular electrodes to a mechanical mating method to provide good electrical continuity across the modular torch system, the modular hybrid plasma reactor ran smoothly. Figure 29 shows the current, voltage, power, and temperature measurements for the hybrid plasma system for hybrid run $\mathrm{T} 225$ to produce $\mathrm{WO}_{3}$. The data show the system responded smoothly during operation.
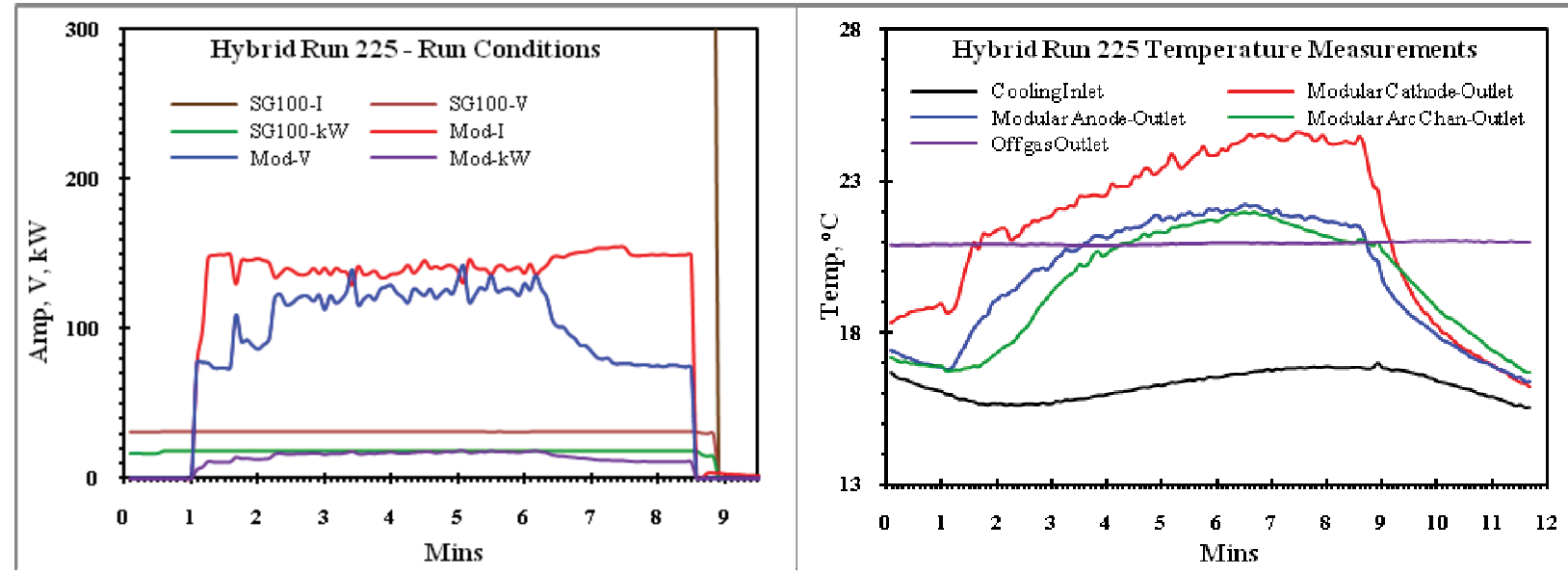

Figure 29. The current, voltage, and power of the hybrid run $\mathrm{T} 225$ for $\mathrm{WO}_{3}$ production are shown in (a), and the temperature measurement for all components in the hybrid system is shown in (b). 
The nanoparticles produced in run 225 are shown in Figure 30, a, b and c. Particles range from $<10$ $\mathrm{nm}$ to $>100 \mathrm{~nm}$. As seen in Figure 30c, the majority of the nanoparticles were less than $50 \mathrm{~nm}$.

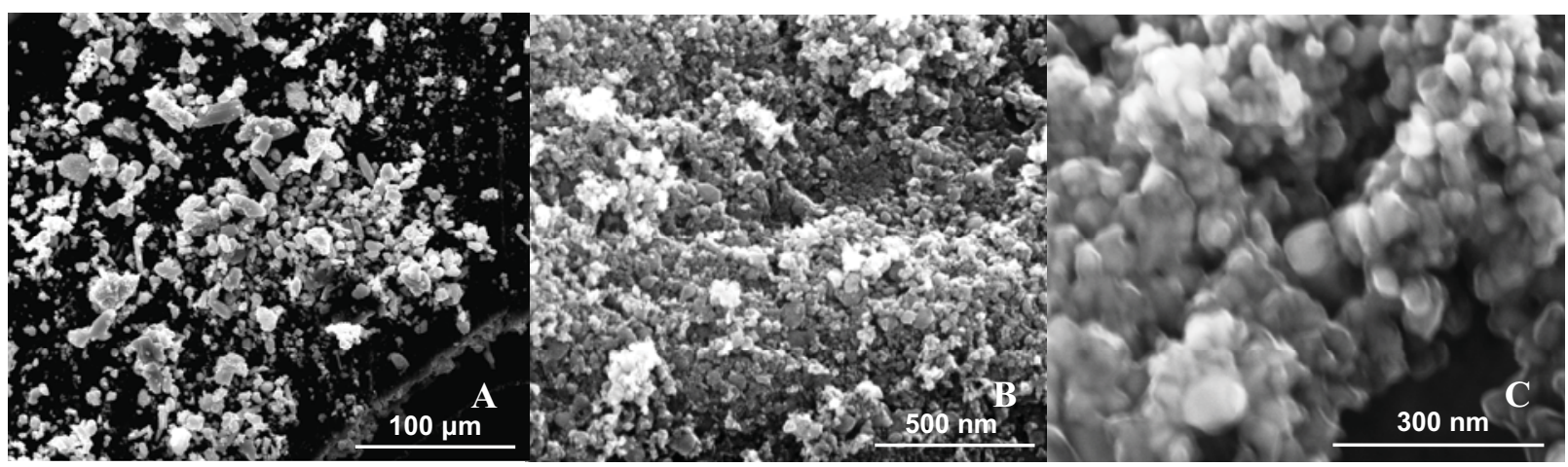

Figure 30. Scanning electron micrographs for the (a) starting $\mathrm{WO}_{3}$ particles, (b) hybrid plasma produced $\mathrm{WO}_{3}$ nanoparticles, and (c) higher magnification of the nanoparticles.

\subsection{Run 227 1-Hour Run}

Run 227 was the first in a series of sustained runs to demonstrate the long-term operability of the modular hybrid plasma system for high production rates of nanoparticles. The power supply for the modular plasma unit was set at 400 volts open voltage to accommodate the requirement for a high powder feed rate. Joule heating from an arc current provided the temperature necessary for melting and vaporizing the $\mathrm{WO}_{3}$ feed. After vaporization, partial ionization of the vapor would require the arc voltage to increase to maintain the arc. The arc current would decrease to compensate for the voltage increase. However, under a constant powder feed rate, vapor ionization was constant and would not be a major factor for a significant arc voltage increase. A factor that would cause a significant arc voltage increase was high powder loading into the arc and increased degree of vapor ionization. Pulsations in powder feeding would momentarily overload the arc with powder and disturb the equilibrium processing condition of the system. Even the best powder feeder would exhibit some feeding pulsations. Figure 31 shows the current, voltage, and power characteristics for run 227. During the run multiple momentary voltage spikes were observed. The current dropped when each voltage spiked, and the plasma intensity dimmed. The joule heating also decreased with each current drop, and this phenomenon affected materials vaporization. It was possible that the voltage spikes were associated with large pulses of $\mathrm{WO}_{3}$ entering the modular cathode region. During the run, powder feed-rate fluctuations, which displayed on the powder feeder, were observed. Even with the best powder feeder, a constant powder feed rate would be difficult to achieve. The voltage spikes in Figure 31 could be indicative of this event.

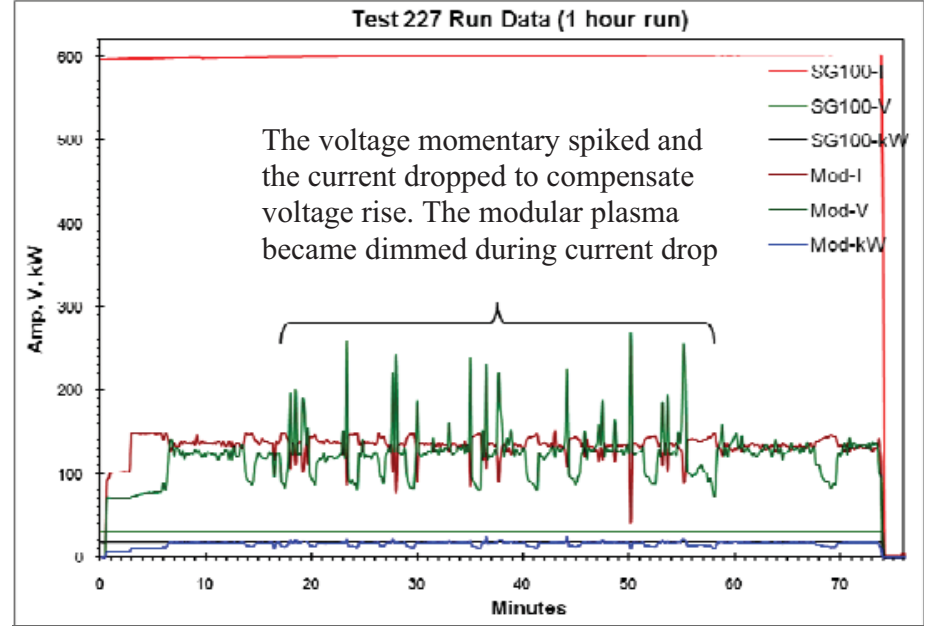

Figure 31. The data show the current, voltage, and power characteristics for run 227. 


\subsection{Run 228 2-Hour Run}

Run 228 was the second in a series of sustained runs to demonstrate the long-term operability of the modular hybrid plasma system for high-rate production of nanoparticles. In this run, the open voltage of the power supply was set at $400 \mathrm{~V}$ for the modular plasma unit to accommodate pulses of high powder loading into the arc. A limited amount of air, equivalent to $2.5 \%$ of oxygen in the plasma gas, was also introduced into the plasma to counter the slight reduction of the powder. The introduced air also required a higher voltage to sustain the arc because of a higher ionization potential required of oxygen as compared to nitrogen. In Figure 32 the pluses of high powder loading into the modular unit are also evident. Most of the time, when the arc voltage spiked to higher voltages, the current did not drop below 100 amps and the joule heating remained sufficient to continue vaporizing the feed powder. However, during voltage spikes in run 227, the arc sometimes would extinguish. The modular unit would need to manually restart, or the powder feeding would need to be interrupted so the modular plasma unit could self restart. Another significant difference in run 227 was that, when the voltage spiked without arc extinction, the arc current would drop below 100A, and the joule heating

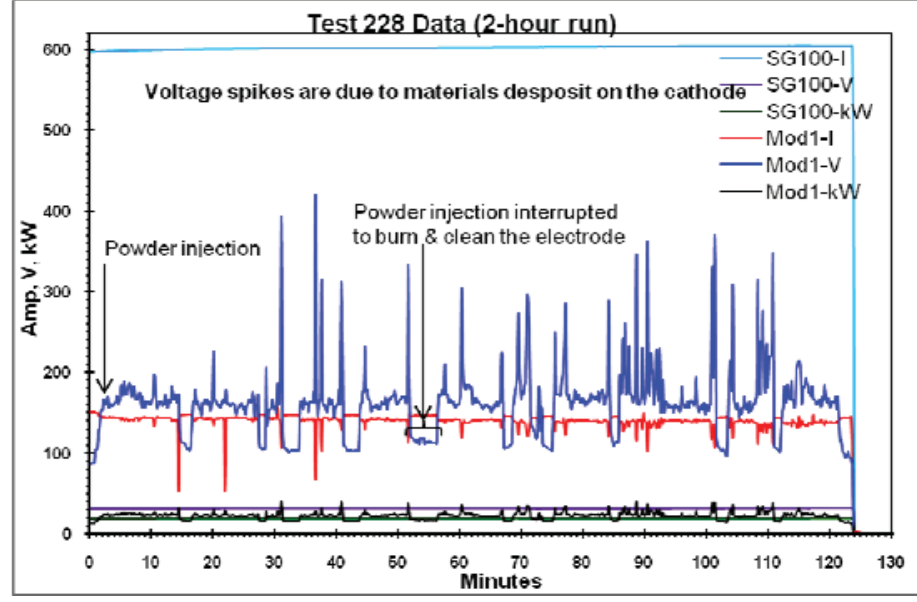

Figure 32. The data show the current, voltage, and power characteristics for run 228. capability of the arc dropped substantially. While in run 228 the arc current seldom dropped below 100A when the arc voltage spiked, it thus maintained substantial joule heating for powder vaporization. Even during arc voltage spikes the arc was never extinguished. Occasionally after the voltage spiked in run 228, the powder injection was interrupted for a short time to burn and clean the tungsten electrode surface. A semi-clean electrode surface would also decrease the arc voltage. One hundred grams of run 228 powder was sent to PPG Industries for materials characterizations. X-ray diffraction analysis, Brunau, Emmett, and Teller (BET) surface-area measurement, and transmission electron microscopy (TEM) particle morphologies were performed. In X-ray diffraction analysis, besides $\mathrm{WO}_{3}$, a trace amount of $\mathrm{WO}_{3-\mathrm{x}}$ was detected in the produced powder. The trace amount reduced oxide reflected a slightly greenish tint in an otherwise yellow powder. TEM morphologies of the modular hybrid plasma produced $\mathrm{WO}_{3}$ are shown in Figures 33 a-c. The TEM pictures showed most of the nanoparticles were round. The pictures showed the particles were between 10 and $200 \mathrm{~nm}$.
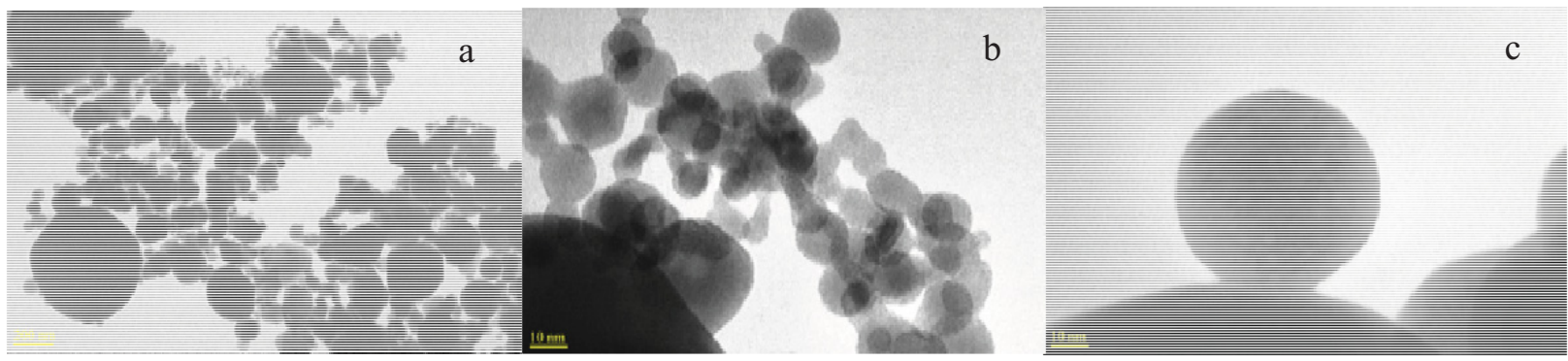

Figure 33. (a), (b), and (c) TEM morphologies of the $\mathrm{WO}_{3}$ nanoparticles synthesized using the modular hybrid plasma system. 
There were a few large faceted particles $>200 \mathrm{~nm}$. The particle in Figure $33 \mathrm{c}$ was $54 \mathrm{~nm}$, and the individual grain measured on this particle was $2 \mathrm{~nm}$. The BET measurement showed a specific surface of $5.7 \mathrm{~m}^{2} / \mathrm{g}$. The calculated equivalent particle size was about $147 \mathrm{~nm}$. The feed material had an average particle size of about $44 \mu \mathrm{m}$. The apparent low surface area was due to the presence of some large particles, which would affect the measurement. A second factor was that these were dense nanoparticles with no internal surface. Figure 34 shows the condition of the collection chamber at the beginning of run 228 and 5 minutes into the run. Figure $34 \mathrm{a}$ shows the $\mathrm{WO}_{3}$ nanoparticles immediately filled the collection chamber at the beginning of run 228. The plasma tail flame was not visible in the chamber because of air quenching at the modular anode exit. Figure $34 \mathrm{~b}$ shows a substantial layer of whitish nanoparticles condensed on the surface of the collection chamber window after 5 minutes into the run. Nothing is observable through the chamber window. After the run, the modular plasma system was disassembled to collect the product and to examine the condition of each component.

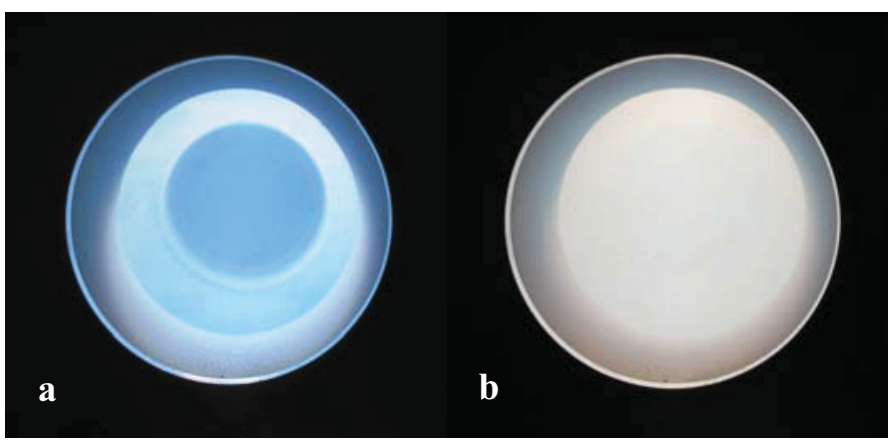

Figure 34. (a) Shows the powder suspended in the chamber at the beginning of run 228; the color of the plasma light is slightly bluish, and (b) shows the collection chamber window had a substantial layer of nanoparticles condensed on the surface 5 minutes into run 228; nothing was observable through the chamber window.

Figure 35 shows the condition of the modular plasma torch. After the 2-hour run both the modular cathode (5a) and the modular anode (5b) showed a thick layer of molten tungsten oxide on the surface of the ceramic insulation and the $\mathrm{W}$ ring electrodes. This thick coating affected the arc root attachment to the tungsten electrode surface and contributed to high arc voltage fluctuations. Thick material coating on the electrodes must be minimized or eliminated to give the modular torch stable long-term operability. This thick coating might be associated with high pulses of powder feeding. This critical parameter must be optimized. Some condensed material growth was observed at the anode exit, and this growth was due to quench air to minimize $\mathrm{WO}_{3-\mathrm{x}}$ formation. A better design of the quenching at the anode exit would eliminate this material growth. Most likely, the larger nanoparticles were coming from this condensed material and contributed to a low specific surface measurement. Powder was collected in the expansion chamber and the bag filter for analysis.

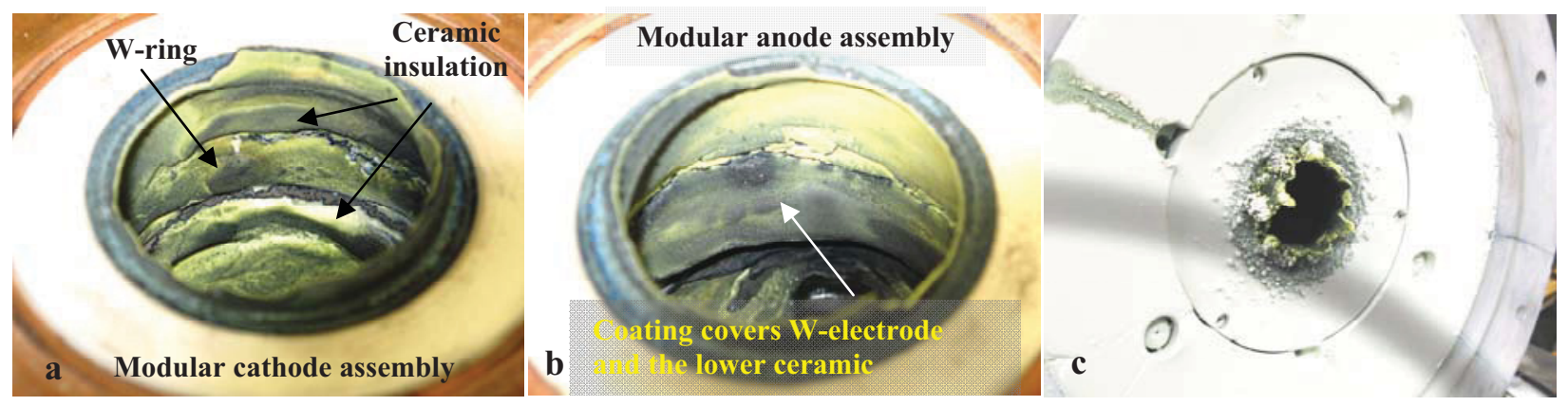

Figure 35. Conditions of the modular plasma electrodes after the 2-hour run: (a) the cathode assembly, (b) the modular anode assembly, and (c) anode exit. 
Figure 36a shows the powder collected in the chamber. The powder has a pale yellow color that is a shade lighter than the original feed $\mathrm{WO}_{3}$. Some large particles were seen at the bottom of the chamber. The particles likely came from the condensed materials in the modular anode exit and the arc channel. The presence of these large particles would affect the BET measurement and would give a much lower specific surface area. If

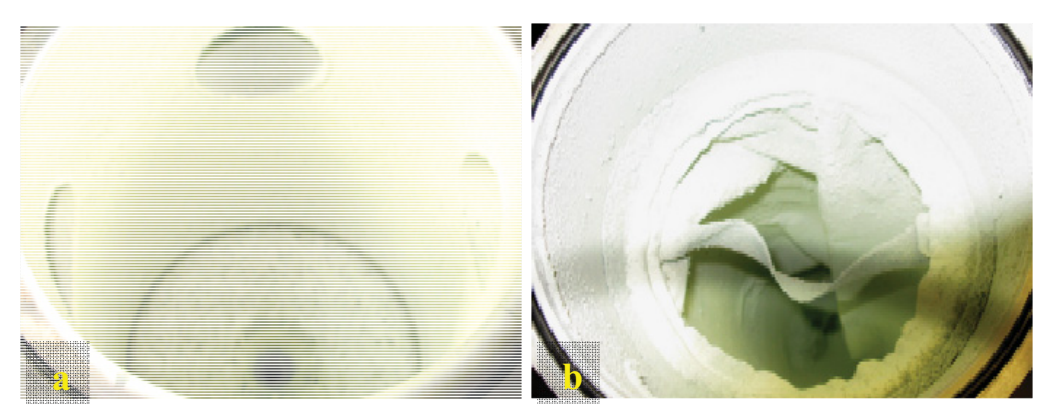

Figure $36 . \mathrm{WO}_{3}$ nanoparticles collected in the (a) collection chamber and (b) the bag filter. these particles could be removed from the product, a significantly higher surface BET measurement would result. Figure $36 \mathrm{~b}$ shows the powder collected in the bag house; this was much more homogeneous and contained very little large particles.

\subsection{Run 229 4-Hour Run}

Run 229 was the third in a series of sustained runs to demonstrate the longterm operability of the modular hybrid plasma system for high-rate production of nanoparticles. In this run two power supplies were stacked in series to obtain an open voltage of $800 \mathrm{~V}$ for the modular plasma unit to accommodate pulses of high powder loading into the arc. A higher open-circuit voltage would allow the power supplies to draw more voltage that was needed to sustain the arc without dropping the arc current significantly when high pulses of powder feeding occurred. The data in Figure 37 clearly shows that the arc current did not fluctuate much when the voltage spike occurred. After the initial burst of high powder loading into

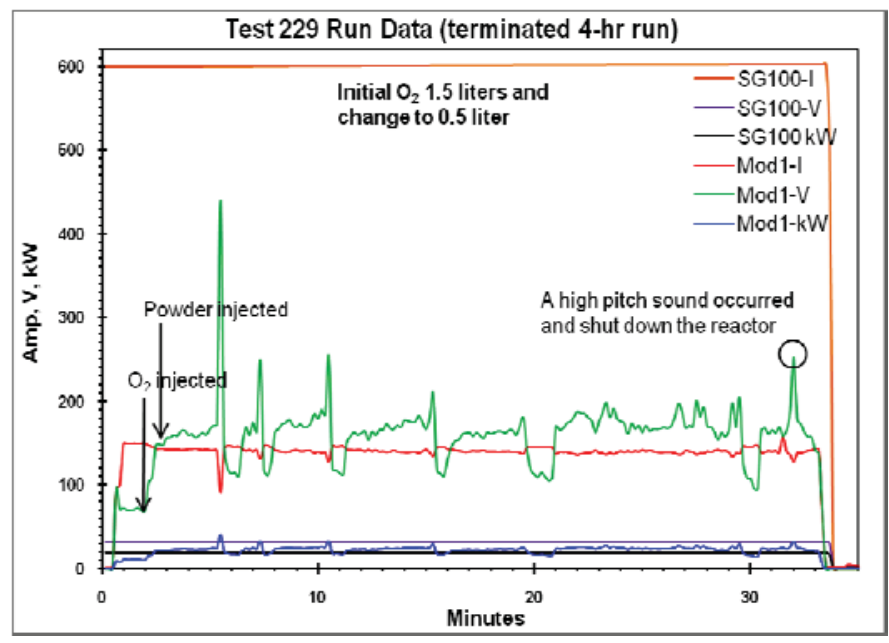

Figure 37. The data show the current, voltage, and power characteristics for run 229 before the run was terminated. the arc, the magnitude of the subsequent voltage spikes was also much lower than in runs 227 and 228. After 30 minutes of powder feeding, two unexpected events occurred. First, the ceramic plate between the modular cathode and the arc channel cracked sometime during the run. Second, after 32 minutes into the run, a high-pitched sound developed, and one side of the cracked ceramic plate separating the modular cathode and the arc channel glowed red. This is an indication of uneven heat loading to the modular plasma torch. The run was terminated to prevent significant damage to the system. Powder was collected for analysis and the system was disassembled for study. 
Figure 38 shows the damage that was done to the system. Figure 8a shows a hole drilled by the cathode arc root at the junction of the ceramic plate and the top of the arc channel. This occurred when the cathode arc root momentarily moved downward from the tungsten ring to the top of the arc channel. Figure $38 \mathrm{~b}$ showed the ceramic plate cracked into two pieces due to uneven thermal stress during this arc-root excursion event.

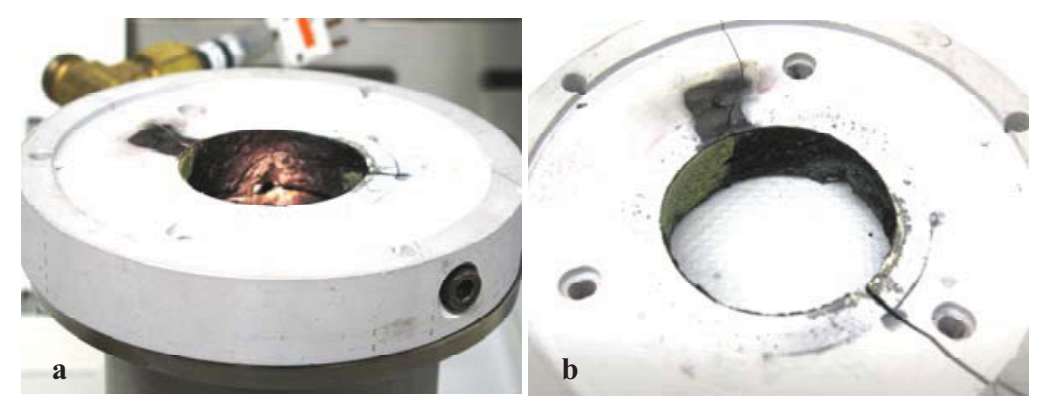

Figure 38. (a) A hole drilled at the junction of the ceramic plate between the modular cathode and the arc channel, and (b) the ceramic plate cracked due to thermal stress.

After the system was disassembled it was discovered that significant feed material condensed between the modular plasma torch and the upstream plasma torch. The material formed a disc cone covering the ceramic plate channel connecting the two torches. Figure 39 shows the material cone formed between the two plasma torches. Swirl gas ports in this ceramic plate provide a thin sheath of high velocity swirl gas to decrease material condensation on the modular cathode unit.
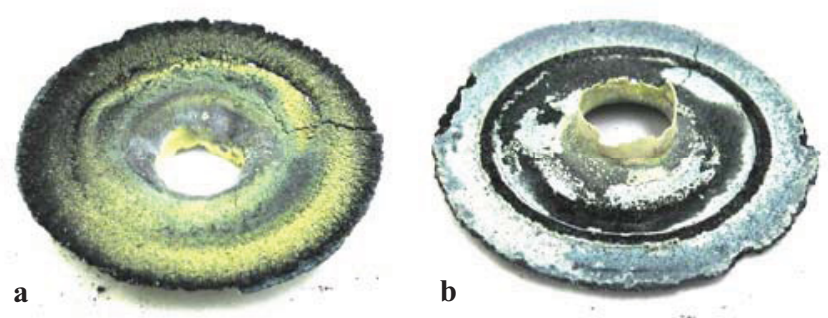

Figure 39. (a) Top and (b) bottom sides of the $\mathrm{WO}_{3}$ cone.

The swirl gas may have cooled the plasma boundary layer too much, actually causing more deposition of the feed materials on the ceramic plate. The cathode and anode channels were covered with a thick layer of condensed tungsten oxide. Figure 40 shows the thick coating formed inside the cathode channel, and the same condition was also observed in the anode channel. The anode and cathode assemblies showed heavy tungsten oxide deposit. The heavy deposit formed on the modular electrode assemblies may have given rise to higher surface resistivity of the ring electrodes and changed the electrical conductivity for

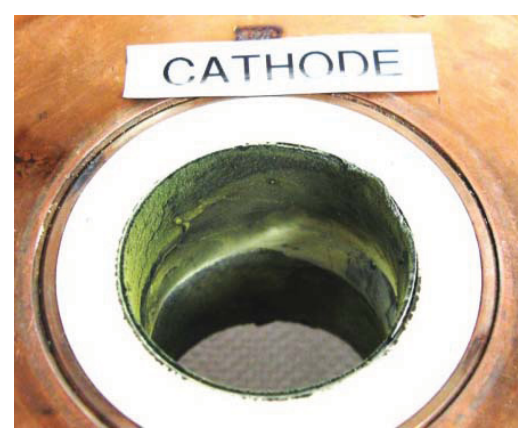

Figure 40. The thick coating formed on the cathode channel. the whole electrode assembly. Extensive reconditioning of the electrode assemblies would be necessary before resuming sustained high-rate powder feeding runs and process optimization. One hundred grams of Run 229 powder were sent to PPG Industries for materials characterizations. X-ray diffraction analysis, BET surface area measurement, and TEM particle morphologies were performed. The measured BET surface area was $6.8 \mathrm{~m} 2 / \mathrm{g}$. The calculated equivalent particle size is about $123 \mathrm{~nm}$. The particle size was slightly smaller than test 228 . 


\subsection{Unsuccessful Second 4-Hour Runs}

After the first unsuccessful 4-hour run, the modular torch system was dismantled, and each component was thoroughly cleaned and reassembled for another 4-hour run. The second run was smooth after the an early glitch in which one of the powder feeders was not feeding powder to the hybrid plasma system. Only after the powder feeder was cycled on and off several times did powder feeding began. With the exception of voltage spikes and modular electrodes burn-off, the run was consider normal. However, about an hour into the run a plume of powder was released from the reactor. The whole hybrid torch system was lifted slightly sideway from the collection chamber. There was a pressure build up and a rapid release of gas from the system. The run was immediately terminated and the cause for this abnormal event investigated. The data for this run are shown in Figure 41. A considerable number of voltage spikes occurred, but the frequency of occurrence was less compared to the $400 \mathrm{~V}$ opencircuit runs. The magnitude of the voltage spikes were also reduced. The most noticeable difference is that the current for the high-open-voltage runs was significantly more stable than the lowopen-voltage runs. The overall plasma intensity was brighter. Higher joule heating for the feed powder was maintained in the high-open-voltage cases.

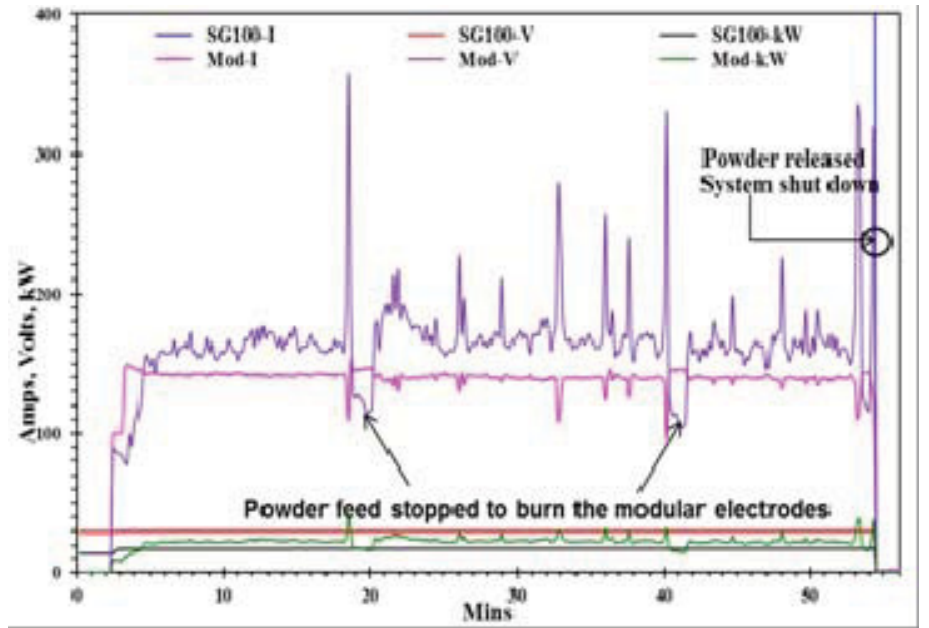

Figure 41. Terminated $2^{\text {nd }} 4$-hour run shows the high voltage spikes. During voltage spikes, the current drop was rather small, and joule heating was maintained.

After the hybrid system was disassembled, a semi-porous powder plug was found in the transfer line before the bag filter. This plug caused a pressure build-up during the run and led to powder released from the collection chamber. This powder plug formation was never observed in any other run. The cause of this abnormal event is unknown; it is possible that one problematic powder feeder malfunctioned during the run. Apart from lumpy materials from the torch system, the powder collected in the collection chamber and bag filter looked extremely good. Figure 42 shows the semi-porous powder plug formed in the transfer line and the good-quality powder collected in the bag filter.
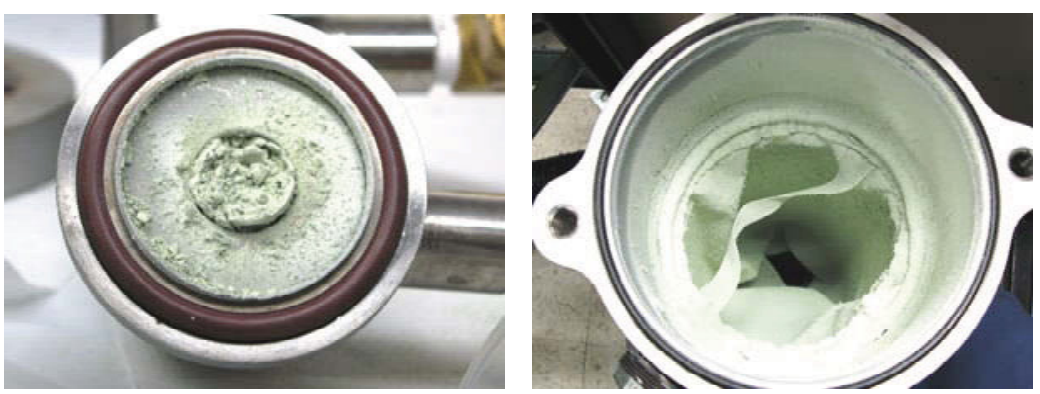

Figure 42. A semi-porous powder plug formed in the transfer line and the powder collected in the bag filter. 
The modular anode and cathode channels were completely covered with a layer of tungsten oxide coating (Figure 43). This happened in all runs. Materials deposited on the surface of the insulation is tolerable; however, material deposition on the ring electrode surface must be avoided. Powder injected into the upstream plasma torch was preheated and initially melted or partially vaporized by the upstream plasma.

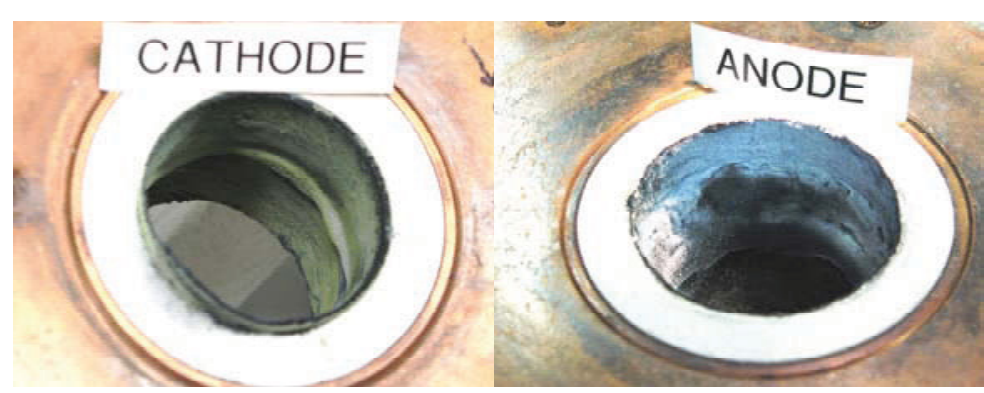

Figure 43. Both the cathode and anode channels show a heavy coating of tungsten oxide covering the tungsten ring electrodes. The coating caused significant arc voltage fluctuations.

The molten particles then entered the modular plasma torch for further vaporization. A swirl gas was injected through a ceramic plate separating the upper plasma torch and the modular cathode of the downstream modular plasma torch. The idea of the swirl gas was to prevent any material deposition on the surface of tungsten electrodes. However, the cold swirl gas coming from above may have exacerbated the condensation problem on the modular plasma torch. The cold swirl gas cooled the vapor and molten material and deposited the material on the surface of the electrode. Materials deposited on the surface of the electrodes also compounded the voltage requirement of the process. This technical hurdle must be rectified to make the hybrid plasma system and production process optimum.

A potential solution is to clean the surface of the electrodes with a thin sheath of very-high-velocity swirl gas that is also heated by the arc roots. A radical new design will be needed to incorporate a swirl gas injected through the electrodes. The swirl gas will be heated by the arc roots and will help to rotate the arc faster than the current design in order to prevent material deposition. The new design also reduces the size and weight of the current modular torch system and makes it more compact and portable. The new design is shown in Figure 44.

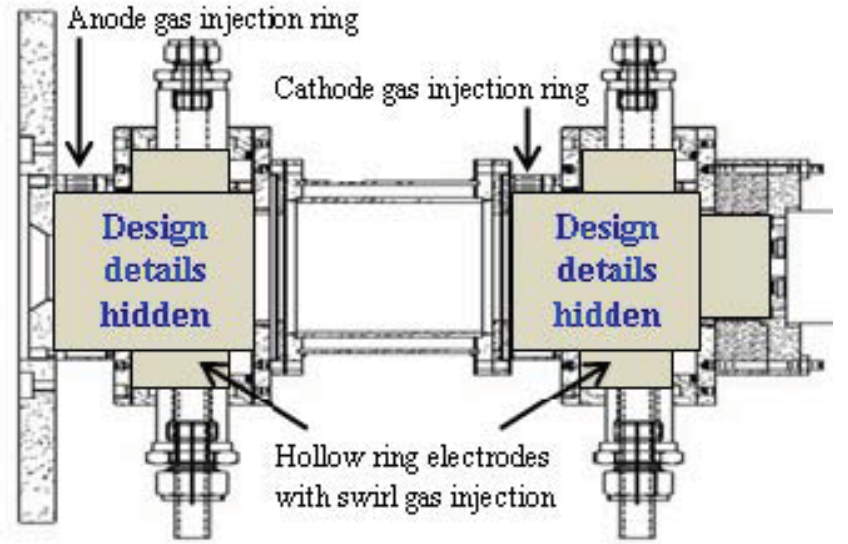

Figure 44. New designs of the modular plasma torch system.

Significant features of the new design include:

- Hollow ring electrodes, with high-velocity swirl-gas bleeding to clean the electrode surface of material deposition

- Electrode swirl-gas enhanced arc rotation to reduce arc-root attachment time and minimize electrode wear

- A self-induced magnetic field to stabilize arc root attachment on the surface of the electrodes

- Induced moving charges on the surface of hollow ring electrodes to rotated the arc roots at high speed to reduce electrode wear

- Mechanically mated components

- Flexibility to modify the hollow ring electrodes without the need to build new sub components 
- Flexibility to test different electrode materials.

While fabrication of the modified new modular plasma torch components was in progress, we performed vaporization of pure $\alpha$-phase large $\mathrm{Al}_{2} \mathrm{O}_{3}$ powder in the current hybrid plasma system. The powder collected in the reactor chamber and the bag filter were different. In the reactor chamber, the powder consisted of $34 \% \alpha-\mathrm{Al}_{2} \mathrm{O}_{3}$ and $64 \%$ of $\delta-\mathrm{Al}_{2} \mathrm{O}_{3}$. The average particle size was $28 \mathrm{~nm}$ and the surface area was 25.3 $\mathrm{m}^{2} / \mathrm{g}$. Interestingly, the bag house contained a single phase of $\delta-\mathrm{Al}_{2} \mathrm{O}_{3}$ nanoparticles. The average particle size was $9 \mathrm{~nm}$ and the surface area was 74.3 $\mathrm{m}^{2} / \mathrm{g}$. This result is surprising because $\delta$ $\mathrm{Al}_{2} \mathrm{O}_{3}$ is a meta-stable material and is almost impossible to synthesize as a single phase. This technology may possess the capability to synthesis high value single phase meta-stable materials impossible to produce with conventional technologies. Figure 45 shows the $\mathrm{X}$-ray diffraction analysis of the starting $\alpha-\mathrm{Al}_{2} \mathrm{O}_{3}$ and the bag filter collected $\delta-\mathrm{Al}_{2} \mathrm{O}_{3}$.

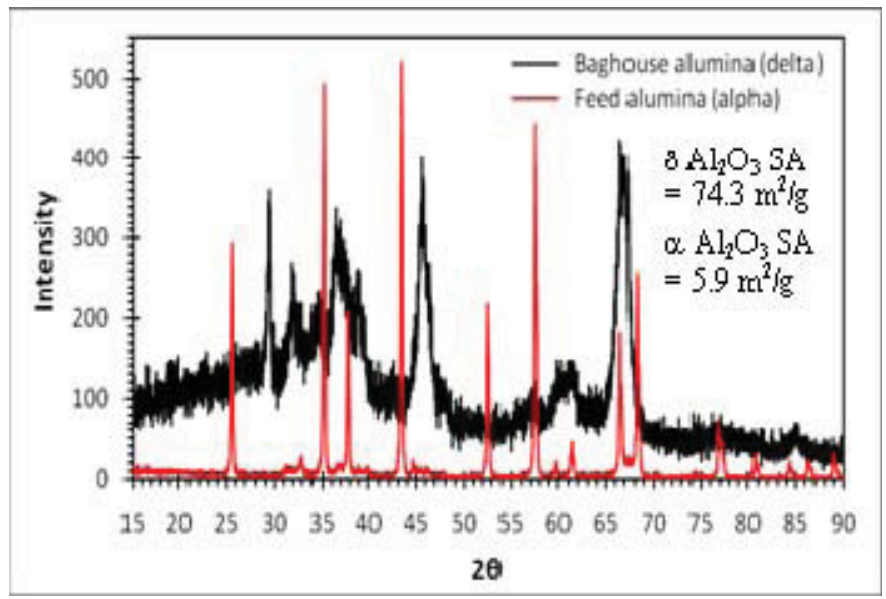

Figure 45. X-ray diffraction analysis of the starting $\alpha$ $\mathrm{Al}_{2} \mathrm{O}_{3}$ and the bag filter collected $\delta-\mathrm{Al}_{2} \mathrm{O}_{3}$.

\subsection{New Modified Modular Plasma Reactor}

The fabrication of the newly modified modular torch was complete near the end of FY-11. No resources or time left to test the new modifications. The new and compact modular hybrid plasma system is shown in Figures 46 and 47. Figure 46 shows the completely assembled new modular hybrid plasma system. On top of the modular cathode is the gas-delivery component, which supplies swirl gas to the hollow ring electrode. However, the gas-delivery component for the modular anode sits beneath the modular anode. Figure 47 details the new modular electrode assembly with the gas-delivery component attached. The modular anode and cathode are identical.

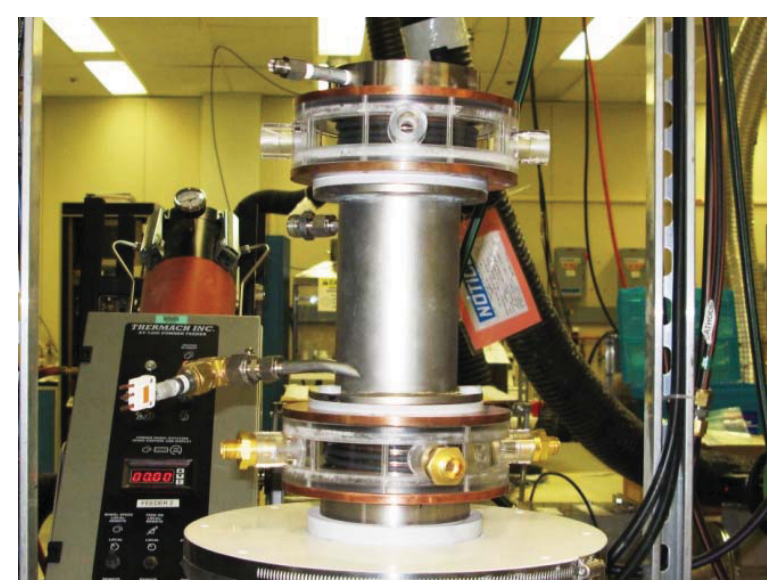

Figure 46. The new modular hybrid plasma torch consists of gas-breathing hollow-ring electrodes for electrode surface cleaning.

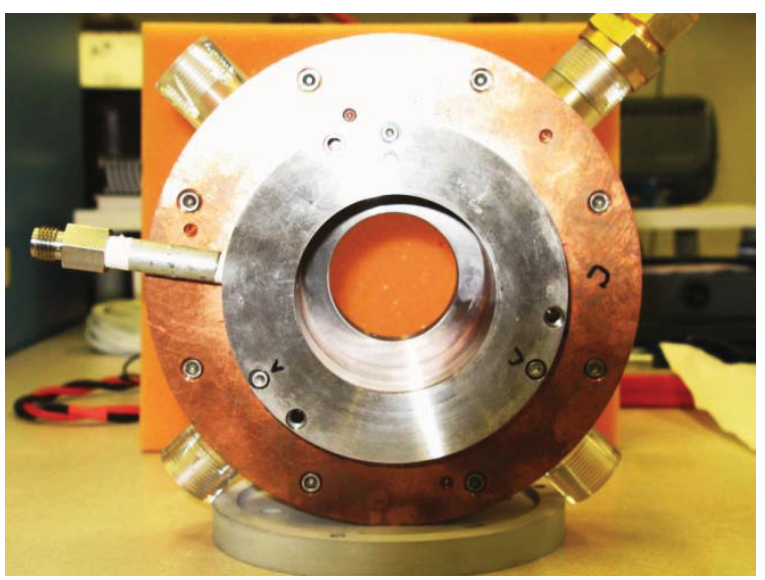

Figure 47. The new modular cathode assembly with a hollow-ring electrode and a gas-delivery component attached to the top of the assembly. 


\subsection{INL 300 kW Pilot Scale Model Projection}

The model projection of the INL $300 \mathrm{~kW}$ pilot-scale modular hybrid plasma reactor was based on the industrial partner's $300 \mathrm{~kW}$ hot-wall plasma reactor. This $300 \mathrm{~kW}$ hot wall plasma reactor was built by PPG, Inc., under a DARPA project and runs with a reversed-polarity plasma torch owned by Phoenix Solutions of Hutchinson, Minnesota. The primary objective of this PPG hot-wall plasma reactor is to synthesize non-oxide ceramic nanoparticles for light-armor applications. The reactor was also tested for pilot-scale synthesis of silica and magnesia nanoparticles. As a part of this CRADA, the task for PPG was to process $\mathrm{WO}_{3}$ in this hot-wall plasma reactor to collect $\mathrm{WO}_{3}$ synthesis data for INL. INL would use the data to make scaling projections for its bench-scale modular hybrid plasma reactor at $300 \mathrm{~kW}$ pilot scale.

\subsection{PPG 300 kW Hot-wall Plasma Reactor}

Figure 48 shows a sketch of the PPG $300 \mathrm{~kW}$ hot-wall plasma reactor. The reactor is a double-wall water-cooled cylinder constructed of stainless steel. The inner diameter of the reactor is $3 \mathrm{ft}$. The thickness of the ceramic insulation is $6 \mathrm{in}$. and consists of two layers of different thicknesses. The outer ceramic insulation is a layer of porous brick, and the inner ceramic insulation is a layer of dense zirconia brick. The insulation cuts down the heat loss to the water-cooled stainless

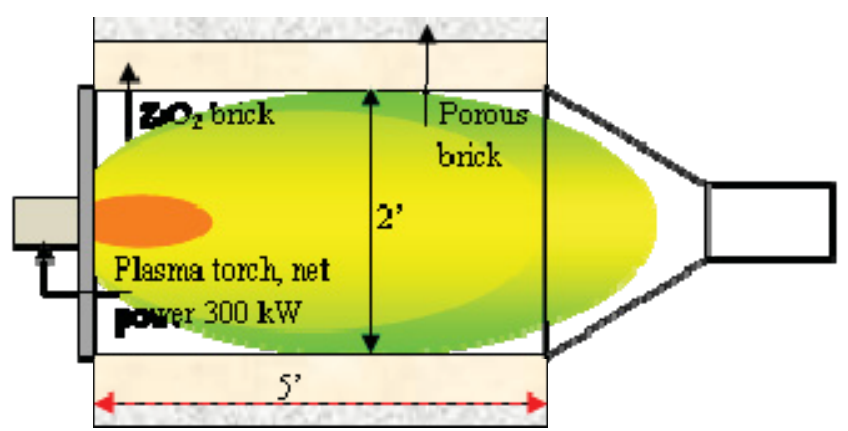

Figure 48. PPG hot wall plasma reactor. steel reactor shell. The diameter of the insulated reaction chamber is $2 \mathrm{ft}$, and the length of the reaction chamber is $5 \mathrm{ft}$. A conical transition section links the reaction chamber to the cooling transfer pipe, where product powders are delivered to bag filters. The cooling transfer pipe is designed to remove $100 \mathrm{~kW}$ of heat load. The reactor includes provisions for high volumes of quench-gas injection to cool the gas temperature rapidly. The modeling results for the axial and radial temperature profiles in the reactor are shown in Figure 49. The reaction zone temperature is between $2000-3500 \mathrm{~K}$ and extends into the conical section. This temperature is sufficient to keep $\mathrm{WO}_{3}$ in vapor form because the boiling temperature for WO3 is $2000 \mathrm{~K}$.

The heat source is a Phoenix Solutions $300 \mathrm{~kW}$ reversed-polarity plasma torch. In the reversedpolarity plasma torch, the anode is placed upstream of the cathode. During plasma operations, a portion

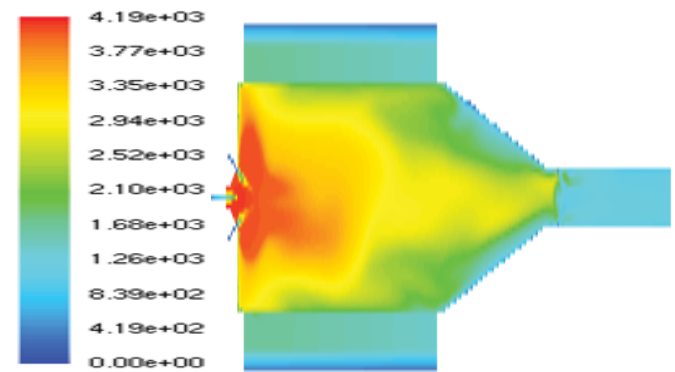

Figure 49. Modeled temperature profiles for the PPG $300 \mathrm{~kW}$ hot-wall plasma reactor. of the arc column "peeks" outside the plasma torch body. Due to this peeking effect, the arc column is longer than a normal-polarity plasma torch in which the arc column is completely confined within the plasma torch body. The operating voltage for a reversed-polarity plasma torch was a little higher than a normal-polarity plasma torch; thus, more power dissipation is required for operation.

PPG performs modeling for a silicon oxide particle vaporization behavior in the reactor. The maximum gas temperature inside the reaction chamber predicted by the model is $4193 \mathrm{~K}$. The silica particle would take $12 \mathrm{~ms}$ (green arrow in Figure 50) to reach $2500 \mathrm{~K}$, the vaporization temperature of silica. The particle would stay at that temperature until the entire particle evaporated. Tungsten oxide melts at $1740 \mathrm{~K}$ and boils at $2000 \mathrm{~K}$. It would take $10 \mathrm{~ms}$ (red arrow in Figure 50) for tungsten oxide to 
reach $2000 \mathrm{~K}$ the vaporization temperature. The particle would stay at that temperature until the entire particle evaporated. The modeling also shows the distance the particle would travel in the reactor before reaching the vaporization temperature. For silica, the distance the particle travels is $14 \mathrm{~cm}$ (green arrow in Figure 51) before heating up to vaporization temperature at $2500 \mathrm{~K}$. The particle would stay at that temperature until complete vaporization. For tungsten oxide, the distance the particle travels is $12 \mathrm{~cm}$ (red arrow in Figure 51) before reaching vaporization temperature at $2000 \mathrm{~K}$. Modeling indicates that, for large feed particles $(>180 \mu \mathrm{m})$, the minimum length for the reactor maintained at high temperature to vaporize the feed completely would be $1.06 \mathrm{~m}(3.5 \mathrm{ft})$. Based on this result, PPG built a $5 \mathrm{ft}$-long hot-wall plasma reactor using a $300 \mathrm{~kW}$ reversed-polarity plasma torch for pilot-scale production of nanomaterials. Table 4 shows the operating conditions for the PPG hot-wall plasma reactor.

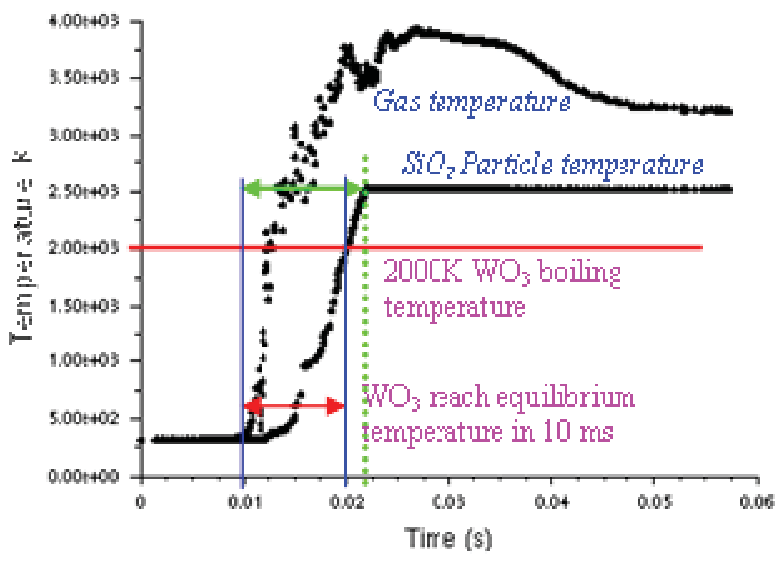

Figure 50. PGG modeling result of the $300 \mathrm{~kW}$ plasma hot-wall reactor, showing the temperature and time profiles for gas and particles.

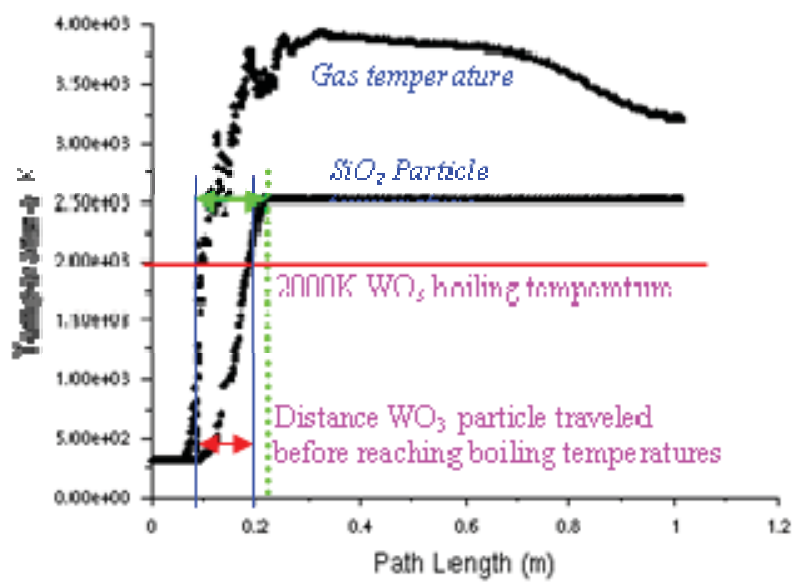

Figure 51. PGG modeling result of the $300 \mathrm{~kW}$ plasma hot-wall reactor, showing the temperature and distance profiles for gas and particles.

Table 4. PPG pilot reactor operating parameters.

\begin{tabular}{|l|l|l|l|l|l|}
\hline & \multicolumn{1}{|c|}{ Torch } & \multicolumn{1}{|c|}{ Sheath gas } & \multicolumn{1}{c|}{ Carrier gas } & \multicolumn{1}{c|}{ Quench gas } & $\begin{array}{c}\text { Total reactor } \\
\text { gas flow }\end{array}$ \\
\hline Flow rates & $500 \mathrm{~L} / \mathrm{min}$ & $198 \mathrm{~L} / \mathrm{min}$ & $82 \mathrm{~L} / \mathrm{min}$ & $1274 \mathrm{~L} / \mathrm{min}$ & $2054 \mathrm{~L} / \mathrm{min}$ \\
\hline Torch Power & $300 \mathrm{~kW}$ net power \\
\hline $\mathrm{WO}_{3}$ feed rate & $50 \mathrm{lb} / \mathrm{hr}$ \\
\hline Specific energy consumption/unit mass processed & $6 \mathrm{kWhr} / \mathrm{lb}$ \\
\hline Pressure & $680-700$ Torr (slightly below atmospheric due to pumping effect) \\
\hline Wall temperature & $800-1100^{\circ} \mathrm{C}$ \\
\hline
\end{tabular}




\subsection{INL $\mathbf{3 0 0}$ kW Modular Hybrid Plasma Scale Model Projection}

The PPG pilot plasma reactor operating condition was used for comparison with the INL bench-scale modular hybrid plasma reactor operating condition. The comparisons were used to project a $300 \mathrm{~kW}$ pilot-scale model for the INL modular hybrid plasma reactor. Since the PPG plasma reactor is operated on $300 \mathrm{~kW}$ net-input power, the net operating power for INL modular hybrid plasma system must be determined before the scale-model projection. The measured efficiency for the modular hybrid plasma system is shown in Table 5. The modular hybrid plasma reactor operating parameters for $\mathrm{WO}_{3}$ synthesis process optimization are shown in Table 6 . In this hybrid arrangement, the modular plasma torch receives net power from the SG100 (upstream) plasma torch besides it own applied power. After heat losses to the modular electrode assemblies and the arc channel, the net power in the modular plasma torch is available for materials synthesis. The data show the modular hybrid plasma system efficiency is very constant under different modular plasma torch operating conditions. The average efficiency for the modular hybrid plasma system is $42.52 \%$. The efficiency is quite high for a combined gross input power of $25.5 \mathrm{~kW}$ to $31.9 \mathrm{~kW}$.

For long term extended runs, the system operating conditions are similar to run 4 and 5 . The average system net power and efficiency for these two runs would be used for scale-model projection. The average total modular hybrid plasma system power is $20.5 \mathrm{~kW}$, and the average hybrid system efficiency is $42.3 \%$.

Table 5. Efficiencies for the INL modular hybrid plasma system (1 modular plasma unit used only).

\begin{tabular}{|c|c|c|c|c|c|c|c|c|c|}
\hline 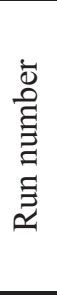 & $\begin{array}{l}\text { SG } 100 \\
\text { Plasma } \\
\text { Torch } \\
\text { Current } \\
\text { (A) } \\
\end{array}$ & $\begin{array}{l}\text { SG } 100 \\
\text { Plasma } \\
\text { Torch } \\
\text { Applied } \\
\text { Power } \\
(\mathrm{kW}) \\
\end{array}$ & $\begin{array}{c}\text { SG } 100 \\
\text { Plasma } \\
\text { Torch } \\
\text { Power } \\
\text { Loss } \\
(\mathrm{kW}) \\
\end{array}$ & $\begin{array}{c}\text { SG } 100 \\
\text { Plasma } \\
\text { Torch } \\
\text { Efficiency } \\
(\%)\end{array}$ & $\begin{array}{l}\text { Modular } \\
\text { Plasma } \\
\text { Torch } \\
\text { Current } \\
\text { (A) }\end{array}$ & $\begin{array}{c}\text { Modular } \\
\text { Plasma } \\
\text { Torch } \\
\text { Applied } \\
\text { Power } \\
(\mathrm{kW}) \\
\end{array}$ & $\begin{array}{c}\text { Total } \\
\text { Modular } \\
\text { Hybrid } \\
\text { Plasma } \\
\text { System } \\
\text { Power } \\
(\mathrm{kW}) \\
\end{array}$ & $\begin{array}{c}\text { Modular } \\
\text { Hybrid } \\
\text { Plasma } \\
\text { System } \\
\text { Power } \\
\text { Loss } \\
(\mathrm{kW}) \\
\end{array}$ & $\begin{array}{c}\text { Modular } \\
\text { Hybrid } \\
\text { Plasma } \\
\text { System } \\
\text { Efficiency } \\
(\%) \\
\end{array}$ \\
\hline 1 & 606.1 & 19.5 & 10.7 & 45.3 & 88.8 & 6 & 14.8 & 8.4 & 43.2 \\
\hline 2 & 606.4 & 19.4 & 10.7 & 45.2 & 96.6 & 6.7 & 15.5 & 8.9 & 42.4 \\
\hline 3 & 606.7 & 19.5 & 10.7 & 45.2 & 116 & 8.5 & 17.3 & 9.9 & 42.4 \\
\hline 4 & 606.9 & 19.4 & 10.7 & 45.1 & 146.8 & 11.2 & 19.9 & 11.5 & 42.6 \\
\hline 5 & 607.3 & 19.5 & 10.8 & 44.4 & 160.9 & 12.4 & 21.1 & 12.2 & 42 \\
\hline
\end{tabular}


Table 6. INL Bench Scale Modular Hybrid Plasma Reactor Operating Parameters for $\mathrm{WO}_{3}$ synthesis process optimization.

\begin{tabular}{|c|c|c|c|c|c|c|c|c|}
\hline & $\begin{array}{l}\text { SG } 100 \\
\text { Plasma } \\
\text { Torch }\end{array}$ & Sheath & Carrier & \multicolumn{2}{|c|}{$\begin{array}{l}\text { Modular } \\
\text { Plasma } \\
\text { Torch }\end{array}$} & $\begin{array}{c}\text { Total } \\
\text { Hybrid } \\
\text { Torch } \\
\text { Flow }\end{array}$ & $\begin{array}{l}\text { Quench } \\
\text { Gas }\end{array}$ & $\begin{array}{c}\text { Total } \\
\text { System } \\
\text { Gas Flow }\end{array}$ \\
\hline Gas flow rates & $40 \mathrm{~L} / \mathrm{min}$ & $40 \mathrm{~L} / \mathrm{min}$ & $20 \mathrm{~L} / \mathrm{min}$ & & & $\begin{array}{c}100 \\
\mathrm{~L} / \mathrm{min}\end{array}$ & $40 \mathrm{~L} / \mathrm{min}$ & $\begin{array}{c}140 \\
\mathrm{~L} / \mathrm{min}\end{array}$ \\
\hline $\begin{array}{l}\text { Applied } \\
\text { power }\end{array}$ & $20 \mathrm{~kW}$ & & & 20 & & & & \\
\hline $\begin{array}{l}\text { Torch } \\
\text { efficiency }\end{array}$ & $44-45 \%$ & & & & & $42 \%$ & & \\
\hline Net power & $8.8 \mathrm{~kW}$ & & & 28.8 & $\mathrm{~kW}$ & $12.25 \mathrm{~kW}$ & & \\
\hline $\mathrm{WO}_{3}$ feed rate & \multicolumn{8}{|l|}{$2 \mathrm{lb} / \mathrm{hr}$} \\
\hline \multicolumn{5}{|c|}{ Specific energy consumption/unit mass processed } & \multicolumn{4}{|c|}{$6.13 \mathrm{kWhr} / \mathrm{lb}$} \\
\hline \multicolumn{5}{|c|}{ Modular torch reaction channel diameter } & \multicolumn{4}{|c|}{1.75 in. } \\
\hline \multicolumn{5}{|c|}{$\begin{array}{l}\text { Modular arc channel length (the region of the cathode arc } \\
\text { root attachment to anode arc root attachment for HT } \\
\text { heating) }\end{array}$} & \multicolumn{4}{|c|}{9 in. } \\
\hline \multicolumn{5}{|c|}{$\begin{array}{l}\text { Modular hybrid plasma torch reaction zone length (bottom } \\
\text { of SG } 100 \text { plasma torch to the bottom of the modular } \\
\text { torch) }\end{array}$} & \multicolumn{4}{|c|}{$15 \mathrm{in.}$} \\
\hline \multicolumn{5}{|c|}{ Collection chamber } & \multicolumn{4}{|c|}{8 in. diameter; 12 in. long } \\
\hline
\end{tabular}

In the extended $\mathrm{WO}_{3}$ processing runs, the applied power for SG 100 and the modular torches was always set at $20 \mathrm{~kW}$ each. Since the SG 100 plasma torch efficiency is $44 \%$, the net torch power is 8.8 $\mathrm{kW}$. The total modular hybrid plasma system power is $28.95 \mathrm{~kW}$. With a $42.3 \%$ modular hybrid plasma system efficiency, the net power for the hybrid system is about $12.25 \mathrm{~kW}$. In the extended runs, the $\mathrm{WO}_{3}$ powder feed rate was set at $1.12 \mathrm{lb} / \mathrm{hr}$. The specific energy consumption per pound of $\mathrm{WO}_{3}$ processed was $12.25 \mathrm{~kW} / 1.12 \mathrm{lb} / \mathrm{hr}$ or $10.94 \mathrm{kWhr} / \mathrm{lb}$. In one of the prematurely terminated 4-hr runs, one of the powder feeders malfunctioned, and the $\mathrm{WO}_{3}$ feed rate went well over $2 \mathrm{lb} /$ hour. Analysis of the product $\mathrm{WO}_{3}$ powder shows only nanoparticle formation. All excess feed materials were completely vaporized in the hybrid plasma. This indicates that the bench-scale system has processing capacity well over $2 \mathrm{lb} /$ hour under those specific system operating conditions. However, the exact maximum feeding capacity is not established due to insufficient resources and time. Using $2 \mathrm{lb} / \mathrm{hr}$ as the nominal powder feeding rate, the specific energy consumption per pound of $\mathrm{WO}_{3}$ processed is $12.25 \mathrm{~kW} / 2 \mathrm{lb} / \mathrm{hr}$ or $6.13 \mathrm{kWhr} / \mathrm{lb}$. This is identical to the PPG $300 \mathrm{~kW}$ hot-wall plasma reactor. For a $300 \mathrm{~kW}$ (net power) modular hybrid plasma pilot reactor operated at the same efficiency $(42.3 \%)$ as the current bench-scale system, the processing capacity is projected at $300 \mathrm{~kW} / 6.13 \mathrm{kWh} / \mathrm{lb}=49 \mathrm{lb} / \mathrm{hr}$. However, due to the size of scaling, the efficiency of the hybrid plasma pilot system would increase also. At $95 \%$ system efficiency, the $\mathrm{WO}_{3}$ powder processing throughput for a $300 \mathrm{~kW}$ hybrid plasma pilot reactor would be $110 \mathrm{lb} / \mathrm{hr}$.

The electrode diameter for the modular plasma torch is $1.75 \mathrm{in}$., and this defines the reaction zone diameter for the bench-scale system. The modular hybrid plasma channel, where all reactions take place, is $15 \mathrm{in}$. long. Therefore, the volume of the modular hybrid plasma torch (the reaction zone) is $36.08 \mathrm{in}^{3}$, or $0.59124 \mathrm{~L}$. The expansion chamber diameter is $8 \mathrm{in}$., and the length is $12 \mathrm{in}$. The volume is $603.19 \mathrm{in}^{3}$, or $9.885 \mathrm{~L}$. The total volume for the hybrid plasma reactor is about $10.4 \mathrm{~L}$. 
The specific energy consumption per unit mass processed for the PPG $300 \mathrm{~kW}$ pilot and the INL modular hybrid plasma bench systems are about the same $(\sim 6 \mathrm{kWhr} / \mathrm{lb})$. However, the total volume of gas consumption in the INL system is significantly smaller. The amount of gas that passes through the INL modular hybrid plasma reaction zone is $100 \mathrm{~L} / \mathrm{min}$, whereas the PPG $300 \mathrm{~kW}$ hot-wall plasma reactor requires $2054 \mathrm{~L} / \mathrm{min}$ of gas through its reaction zone. The INL bench-scale consumes 20.54 times less gas than the PPG pilot plasma reactor. Assuming the INL $300 \mathrm{~kW}$ pilot reactor uses the same amount of gas as the PPG hot wall reactor, the scaling of the INL $300 \mathrm{~kW}$ pilot reaction zone cross section would be

$$
\pi D_{p s}^{2} / 4=20.54\left(\pi d^{2}{ }_{b s} / 4\right) \quad \text { or } \quad D_{p s}^{2}=20.54 d^{2}{ }_{b s}
$$

Where: $p s=$ pilot scale \& bs $=$ bench-scale

The projected minimum diameter for the INL $300 \mathrm{~kW}$ pilot modular hybrid plasma torch reaction zone would be $D_{p s}=\sqrt{ }(20.54) d_{b s}$. Since the bench-scale modular hybrid plasma reactor diameter was 1.75 in., the $300 \mathrm{~kW}$ pilot reactor would have a minimum reaction zone diameter of about $8 \mathrm{in}$. Assuming the INL $300 \mathrm{~kW}$ pilot reactor had $5 \mathrm{in}$. of refractory ceramic insulation, the total inner diameter of the modular hybrid plasma torch would be 18 in. The reaction-zone diameter could be increased by reducing the refractory insulation thickness. For example, by reducing the insulation thickness to 4 in., the reactionzone diameter would be opened to $10 \mathrm{in}$. Since the INL modular hybrid plasma torch reactor has significant higher temperatures than the PPG $300 \mathrm{~kW}$ pilot hot-wall plasma reactor, a 36 in. reactionchannel length might provide sufficient residence time to vaporize the feed materials. The projected size of the INL $300 \mathrm{~kW}$ pilot reactor would be about $15 \%$ that of the PPG $300 \mathrm{~kW}$ hot-wall plasma reactor. A sketch of the INL $300 \mathrm{~kW}$ modular hybrid plasma pilot reactor is shown in Figure 52. The pilot sketch shows a single modular-unit system. The voltage for a $3 \mathrm{ft}$ arc would be very high and dangerous to handle. The pilot reactor would stack multiple short modular units to reduce the voltage requirement and produce a very long high-temperature processing zone. There would be a net energy cascading effect from the upstream modular plasma units; therefore, the applied power in the

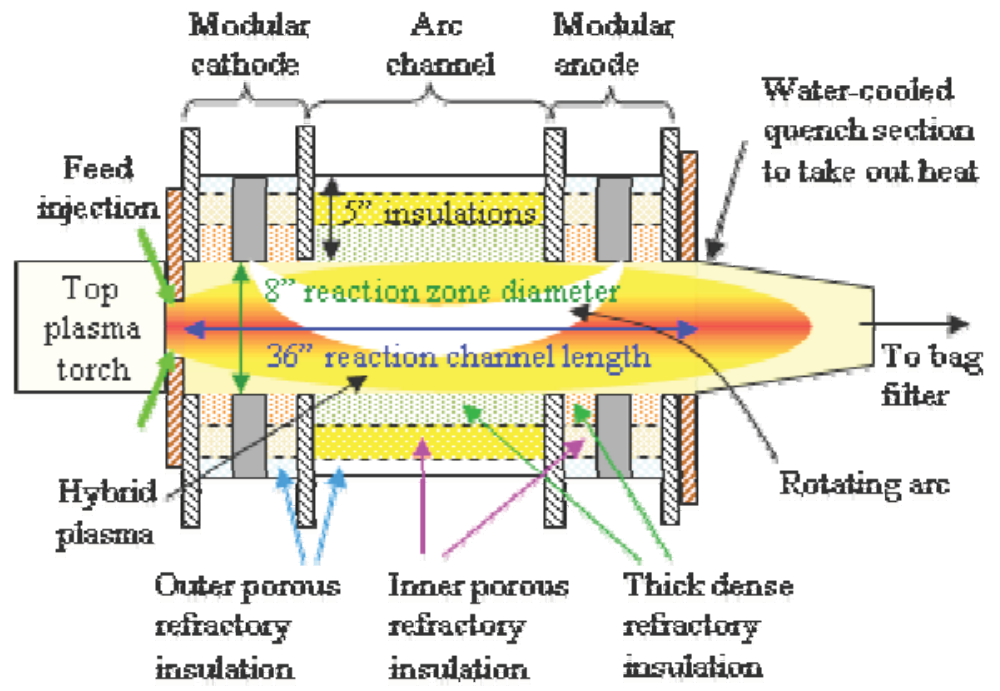

Figure 52. Schematics of the INL $300 \mathrm{~kW}$ one modular unit hybrid plasma pilot reactor. downstream modular plasma units could be reduced. The hybrid system could still maintain an overall large and uniform high-temperature processing zone for the feed materials. The total gas consumption for the INL $300 \mathrm{~kW}$ modular hybrid plasma pilot reactor would be significantly lower than the PPG $300 \mathrm{~kW}$ hot-wall plasma reactor. The total gas flow rate for the INL $300 \mathrm{~kW}$ pilot reactor is expected to be between 300 and $500 \mathrm{~L} / \mathrm{min}$. 


\section{SUMMARY}

INL developed a bench-scale modular hybrid plasma system for gas-phase nanomaterial synthesis. The system is being optimized for $\mathrm{WO}_{3}$ nanoparticles production and scale-model projection to a $300 \mathrm{~kW}$ pilot system. During the course of technology development, several modifications were made to the system to resolve technical issues that surfaced and also to improve performance. All project tasks have been completed with the exception of two optimization subtasks. These two subtasks, 4- and 8-hour continuous powder production runs at $1 \mathrm{lb} / \mathrm{hr}$ powder feeding rate, were impossible to complete due to major technical issues developed with the reactor system. The 4-hour run was attempted twice, and both times the run terminated prematurely. The termination was due to (1) heavy material condensation on the modular electrodes, which led to system operational instability, and (2) pressure buildup in the reactor due to powder clogging of the exhaust gas and product-transfer lines. The modular electrode for the plasma system was significantly redesigned to address the material condensation problem on the electrodes. However, the cause for product powder clogging of the exhaust gas and product-transfer lines that led to a pressure buildup in the reactor remains unknown. Fabrication of the redesigned modular electrodes and additional components was completed at the end of the project life. However, insufficient resource remained to perform tests to evaluate the performance of the new modifications. More development work would be needed to resolve these problems prior to scaling.

The technology demonstrated a surprising capability to synthesize a single phase of meta-stable $\delta$ - $\mathrm{Al}_{2} \mathrm{O}_{3}$ from pure $\alpha$-phase large $\mathrm{Al}_{2} \mathrm{O}_{3}$ powder. The formation of $\delta-\mathrm{Al}_{2} \mathrm{O}_{3}$ was surprising because this phase is meta-stable and only formed between $973-1073 \mathrm{~K}$, and $\delta-\mathrm{Al}_{2} \mathrm{O}_{3}$ is very difficult to synthesize as a single phase. Besides the specific temperature window to form this phase, this meta-stable phase may have been stabilized by nanoparticle size formed in a high-temperature plasma process. This technology may possess the capability to produce unusual meta-stable nanophase materials that would otherwise be difficult to produce by conventional methods.

A $300 \mathrm{~kW}$ INL modular hybrid plasma pilot-scale model reactor is projected using data from PPG Industries' $300 \mathrm{~kW}$ hot-wall plasma reactor. The projected size of the INL $300 \mathrm{~kW}$ pilot model reactor would be about $15 \%$ that of the PPG $300 \mathrm{~kW}$ hot-wall plasma reactor. The material throughput range for the INL pilot reactor would be comparable to the PPG $300 \mathrm{~kW}$ pilot reactor.

The INL hybrid plasma technology is rather close to being optimized for scaling to a pilot system. More near-term development work is still needed to complete the process optimization before pilot scaling. 